\title{
Analyst
}

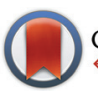

CrossMark

Cite this: Analyst, 2015, 140, 6175

\section{Highly sensitive ligand-binding assays in pre-clinical and clinical applications: immuno-PCR and other emerging techniques}

\begin{abstract}
Mark Spengler, ${ }^{a}$ Michael Adler $^{a}$ and Christof M. Niemeyer ${ }^{\star b}$
Recombinant DNA technology and corresponding innovations in molecular biology, chemistry and medicine have led to novel therapeutic biomacromolecules as lead candidates in the pharmaceutical drug development pipelines. While monoclonal antibodies and other proteins provide therapeutic potential beyond the possibilities of small molecule drugs, the concomitant demand for supportive bioanalytical sample testing creates multiple novel challenges. For example, intact macromolecules can usually not be quantified by mass-spectrometry without enzymatic digestion and isotopically labeled internal standards are costly and/or difficult to prepare. Classical ELISA-type immunoassays, on the other hand, often lack the sensitivity required to obtain pharmacokinetics of low dosed drugs or pharmacodynamics of suitable biomarkers. Here we summarize emerging state-of-the-art ligand-binding assay technologies for pharmaceutical sample testing, which reveal enhanced analytical sensitivity over classical ELISA formats. We focus on immuno-PCR, which combines antibody specificity with the extremely sensitive detection of a tethered DNA marker by quantitative PCR, and alternative nucleic acid-based technologies as well as methods based on electrochemiluminescence or single-molecule counting. Using case studies, we discuss advantages and drawbacks of these methods for preclinical and clinical sample testing.
\end{abstract}

Received 27th April 2015 Accepted 7th July 2015 DOI: $10.1039 / \mathrm{c} 5 \mathrm{an} 00822 \mathrm{k}$ www.rsc.org/analyst

\section{Introduction}

${ }^{a}$ Chimera Biotec GmbH, Emil-Figge-Str. 76 A, D-44227 Dortmund, Germany. E-mail: spengler@chimera-biotec.com

http://www.chimera-biotec.com; Fax: +49(0)231-9742-844

${ }^{b}$ Karlsruhe Institute of Technologie (KIT), Institute for Biological Interfaces (IBG-1), Biomolecular Micro- and Nanostructures, Herrmann-von-Helmholtz Platz 1., D-76344 Eggenstein-Leopoldshafen, Germany.E-mail: niemeyer@kit.edu; http://www.ibg. kit.edu/ibg1/

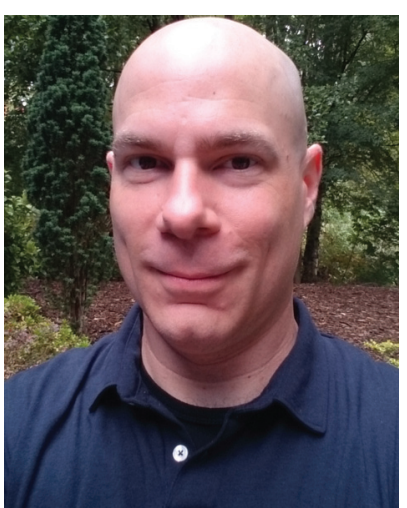

Mark Spengler
Mark Spengler is Director of Project Management and CEO at chimera biotec, a bioanalytical CRO focussing on sensitive immunoassay sample testing. Mark studied biology at the University of Bremen and earned his PhD at the Technical University of Dortmund in the field of directed protein evolution. Mark is author and co-author of several peer reviewed publications and presentations at scientific conferences and an active member of the American Association of Pharmaceutical Scientists (AAPS) emerging technologies committee.

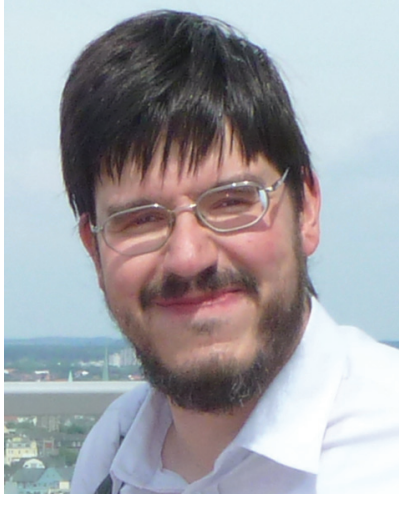

Michael Adler
Michael Adler is co-founder and chief scientific officer at chimera biotec where he is heading the immunoassay development. He studied chemistry at the University of Bremen and earned his PhD with a focus on the development of novel molecular nanoarchitecture from DNA and proteins and their application in the ultra-sensitive ImmunoPCR immunoassay technique. Michael is author and co-author of more than 40 scientific publications. 
Examples of such "Biologics", or generic variants thereof often referred to as "biosimilars", 8,9 include therapeutic, monoclonal antibodies (mAbs), ${ }^{10-14}$ human blood clotting factors, ${ }^{15,16}$ botulinum toxin, ${ }^{17}$ insulin, ${ }^{18}$ cellular growth factors, ${ }^{19-23}$ and recombinant human cytokines. ${ }^{24-26}$ Owing to their generally higher target specificity, such bulky biological molecules provide novel therapeutic potentials, as compared to classical small molecule drugs, ${ }^{27}$ such as the blockbusters Fluticasone ${ }^{28}$ Rosuvastine,${ }^{29,30}$ or Aripiprazole. ${ }^{31}$ However, the development of Biologics brings with it multiple challenges when it comes to bioanalytical sample testing support for tracing these compounds or quantifying the response of their endogenous interaction partners. ${ }^{32-34}$ While quantification of small-molecule drugs and metabolites can often be achieved by mass spectrometry (MS)-based methods, these techniques are usually not well suited for studying Biologics. Even though MS techniques have made progress as means to analyze macromolecules and to detect proteins in clinical settings, ${ }^{35}$ sensitivities are typically considerably above those of conventional ligand-binding assays (LBA), which involve specific antibodies and (enzymatic) signal amplification techniques. ${ }^{36,37}$ In addition, most MS assays for clinical research also require antibody reagents to facilitate the detection of macromolecules, thereby renouncing the main general advantage of MS, that is the label-free detection of molecules-of-interest through their absolute mass without the need for antibody interactions or enzymatic activity. ${ }^{38-41}$

The well-established Enzyme-Linked-Immuno-SorbentAssay (ELISA) technology, first described by Yalow et al. ${ }^{42}$ is considered the gold standard for LBAs. ELISA employs specific binding of antibody reagents to the target of interest and the subsequent signal amplification by enzymatic substrate conversion enabling colorimetric or fluorimetric read-out (for a schematic illustration, see Fig. 4a). The analytical sensitivity of ELISA is limited by the linear nature of the enzymatic activity

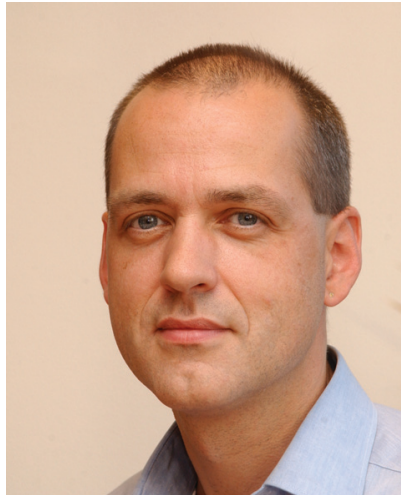

Christof M. Niemeyer
Christof M. Niemeyer is Professor of Chemical Biology at Karlsruhe Institute of Technology (KIT) and Director of the Institute for Biological Interfaces (IBG-1). He studied chemistry at the University of Marburg and obtained his PhD at the Max-Planck Institut für Kohlenforschung in Mülheim/Ruhr. After postdoctorates at the University of New South Wales, Sidney and the Center for Advanced Biotechnology in Boston, he went back to Germany, where he received his habilitation at the University of Bremen. In 2002 he was appointed on the chair of Biological and Chemical Microstructuring at the Technical University of Dortmund before moving to Karlsruhe in 2012. upon conversion of one substrate molecule into one detectable product molecule. In contrast, the so-called DNA-enhanced LBAs usually employ polymerase-chain reaction $(\mathrm{PCR})^{43}$ for signal amplification, thus enabling the exponential amplification of marker molecules. While the relatively young technology of DNA-enhanced LBAs has previously been surveyed, ${ }^{4-52}$ we will here discuss this technology in the context of other emerging techniques for high-sensitivity analyses of biomacromolecules with an emphasis on case studies from preclinical and clinical sample testing in support of pharmaceutical drug development programs. ${ }^{53}$ In this regard, "high sensitivity" refers to an analytical sensitivity which is beyond that of comparable ELISA assays. ${ }^{54}$ Specifically, we discuss technology platforms which have found their way into routine (pre)clinical sample testing, DNA-enhanced immunoassays, electrochemiluminescence (ECL), ${ }^{55}$ single molecule counting (SMC) ${ }^{56}$ and a brief selection of other emerging LBA technologies. ${ }^{57}$

\section{General aspects}

LBAs are used in a vast spectrum of applications ranging from basic academic research to specific analytical and diagnostic issues in clinical and pharmaceutical research and development. Especially in vitro diagnostics (IVD) and pharmaceutical sample testing have their own requirements to meet certain specific regulations. In the following we will focus on considerations for LBAs specific for the pharmaceutical industry. Sample testing in support of drug development programs requires not only consideration of various scientific and practical challenges. These include the expected needs for LBA's sensitivity and dynamic range, potential interferences with endogenous components of the matrix, practical availability of critical assay reagents - most prominently antibodies and analyte standards -, available sample volumes, or specific coordination of timelines (Fig. 1). In addition, the careful attention of recommendations and guidelines on general LBA method development and validation ${ }^{58-63}$ need to be taken into account. For instance, the analytical assay range is defined by accuracy and precision experiments of the standard curve and quality control (QC) samples in a series of three to six independent assay runs. Taking suitable curve fitting models into account, the sensitivity of the assay's upper and lower limit of quantification (ULOQ, LLOQ, respectively) are defined as the highest or lowest standard curve level that can be quantified with acceptable accuracy (\%RE $=\%$ relative error) and precision $(\mathrm{CV} \%=\%$ coefficient of variation). Assay accuracy is expressed as the relative error between a calculated and a nominal concentration, while assay precision reflects the variability of concentration results in sample replication. ${ }^{61,62}$

In general, the recommended acceptance criteria differentiate between pharmacokinetic (PK) studies to quantify drug levels $^{61}$ and biomarker studies to identify suitable markers indicative for a disease or drug treatment. Biomarker quantification is therefore mainly carried out in the discovery phase (Fig. 1) to identify potential lead candidates and to gain 


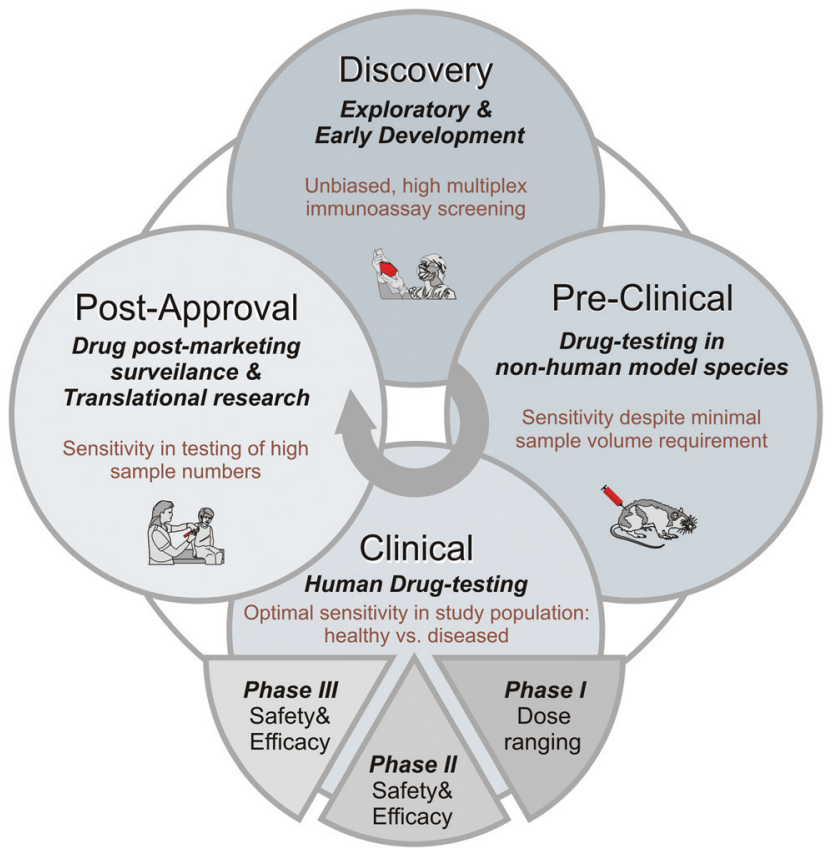

Fig. 1 Key challenges for ligand-binding assays in the four development phases of a macromolecular drug (biologic) from discovery of a given compound for a particular therapeutic purpose over its pre-clinical and clinical testing to drug approval by regulatory agencies and beyond. The clinical phase is usually divided into three sub-phases I III. Phase I trials are usually conducted with small numbers of healthy volunteers to determine drug safety and dosing. The main intention in Phase II trials is to gain initial information on drug efficacy and further investigate safety in small patient numbers. Phase III trials determine safety and efficacy of the drug in larger patient populations, sufficient for statistical evaluation. The main purposes of a given phase within the development of a new drug are printed in italics. The associated main challenges for the bioanalytical sample testing of each phase are indicated in red. Note that biomarker quantification is usually conducted in the discovery phase to identify potential lead candidates and in parallel to the mandatory PK sample testing during the following phases, e.g. to monitor the biological response on the drug's therapeutic mechanism.

pharmacodynamic (PD) information during later phases of the drug development process. PD testing is usually implemented in parallel to the mandatory $\mathrm{PK}$ sample testing, e.g. to monitor the biological response to the drug's therapeutic mechanisms. ${ }^{62}$ Specifically, PK methods should meet fairly stringent acceptance criteria for accuracy (\%RE and CV\% of $\pm 20 \%$ with $\pm 25 \%$ at the extremes of the analytical range at ULOQ and LLOQ). ${ }^{61}$

In contrast, wider acceptance criteria can be applied for biomarker studies. Owing to the generally stronger matrix interference and potential endogenous background in biological specimen, a scientifically reasonable "fit-for-purpose" approach is possible here. ${ }^{62}$ Another key difference between PK and biomarker assays usually concerns the availability of an analyte standard. While the analyte in a PK assay, i.e., the drug, is generally available as well-defined compound, biomarker assays typically require recombinant molecules to be used as standards because the endogenous biomarker is either extremely difficult to obtain or not even accessible. The so- called dilution linearity can then be tested to evaluate whether samples with analyte concentrations above ULOQ can be diluted to fit into the assay's dynamic range. Due to relative high sample concentrations needed, dilution linearity is usually tested with spiked samples. Since the antibody reagents may have different binding characteristics for the artificial standard, which may differ from the endogenous biomarker in e.g. post-translational modifications, the so-called sample parallelism needs to be applied. There, the concentration of the endogenous analyte, determined in a "real", individual biological sample by using a recombinant standard in a standard curve matrix, is compared with concentration values determined at various additional sample dilution ratios over the MRD (minimum required dilution). This procedure is done in order to prove that the endogenous analyte is quantified correctly in real samples despite any differences in between study samples and the standard curve calibration samples. While this sample parallelism represents an important parameter in biomarker assay validation, it is usually not relevant for PK assays.

Another important difference between PK and biomarker studies stems from ethical and regulatory considerations. Due to their availability from other sources, e.g. hospital remnant samples, sample materials containing the analyte (endogenous biomarker) can often be used for biomarker studies. However, great care has to be taken here that the LBA's signal response is not affected by different populations, sampling procedures or storage conditions of the control samples. In contrast, samples already containing the analyte (drug) are usually not available for PK assay development and validation at all.

Typical additional validation parameters like stability and robustness of the assay, or specificity and selectivity in different specimen or study populations are addressed in the regulatory guidelines of LBA method development. ${ }^{58-60}$ It is important to note, that these only provide general guidance for bioanalytical assay development, validation and sample testing. They are often not strictly discriminating between chromatography, mass-spectrometry or immunoanalytic techniques, but mostly make suggestions regarding acceptance criteria to be specifically defined for a given assay during assay development and pre-validation. To specify guidance for immunoassay technologies, the pharmaceutical and bioanalytical community therefore usually publishes "white paper" recommendations for best practice procedures. ${ }^{61-63}$ However, even these much more detailed descriptions do not cover all relevant aspects of a given assay, in particular, when it comes to specifications of emerging technologies, such as the here described high sensitivity LBAs. Since the guidance for established testing procedures can not always be directly transferred to these novel techniques, it is of highest relevance to precisely define and document assay limitations in order to meet the typical validation criteria or at least to enable a scientifically sound argumentation why the higher assay sensitivity requires an adaptation of the common criteria.

In the following, we will briefly discuss some technical issues of relevance for high sensitivity LBAs. Critical assay 
A

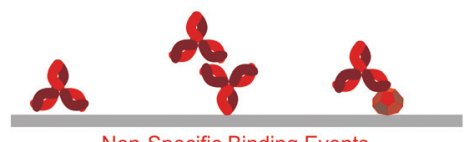

Non-Specific Binding Events

B

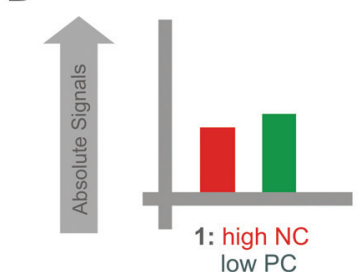

C

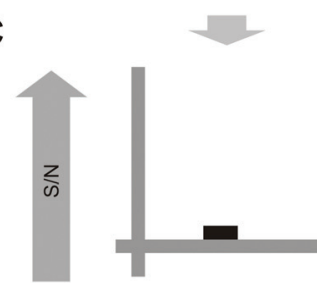

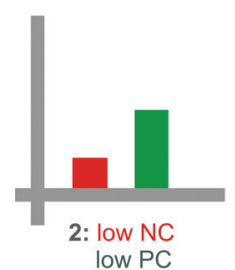

low PC

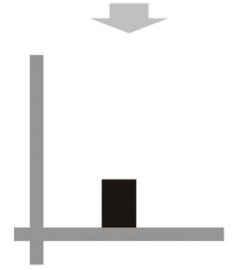

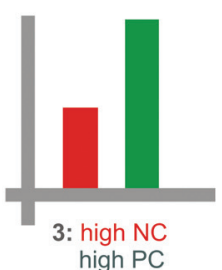

high PC

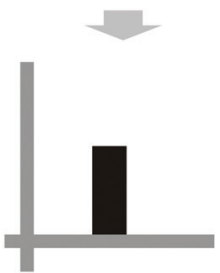

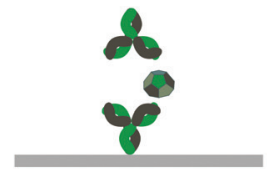

Specific Binding Events

Fig. 2 Schematic illustration of signal-to-noise (S/N) ratios of immunoassays arranged in the order of efficacy for target detection (poor to best). $\mathrm{NC}$ and PC represent arbitrary signal intensities for the negative and positive controls, respectively. Note that these are hypothetical test cases.

reagents include antibodies, aptamers or other oligonucleotides, receptors, binding proteins, peptides or antigens, which specifically recognize the analyte. The specificity and affinity of theses binders determine the performance of all LBAs. ${ }^{61,64-66}$ So-called signal generating reagents $(\mathrm{SGR})^{67}$ are analytebinding molecules tagged to some sort of reporter, such as an enzyme, a dye, fluorophore, or hapten group to enable downstream detection of the binding event. Notably, detection technologies, which employ strong signal amplification have advantages over amplification-free approaches because signal amplification can compensate for low binding affinities. For example, it has been demonstrated that PCR-based signal amplification enabled the use of weak binders which were not well suited for conventional ELISA. ${ }^{68}$ The Signal-to-noise (S/N) ratio reflects the intensity of specific signals with respect to signals originating from negative controls. These background signals typically stem from non-specific binding of SGR to components of the sample matrix, other critical assay reagents, buffer ingredients, or the surface of reaction vials or beads. The optimization of the $\mathrm{S} / \mathrm{N}$ ratio is of key importance to warrant solid bioanalytical sample testing support (Fig. 2). Because high sensitivity LBAs usually amplify specific and non-specific binding events to a similar extent, increased sensitivity not necessarily leads to a gain in $\mathrm{S} / \mathrm{N}$ ratio. ${ }^{69,70}$ Reduction of background signals can be obtained by minimization of non-specific SGR binding through careful choice of reagents, extensive blocking, and, in some cases, by sample dilution (see below).

Non-specific binding of assay reagents are minimized by appropriate blocking reagents, used for coating surface materials and spiking into buffers. ${ }^{45,66,71}$ For high-sensitivity
LBA, however, it is impossible to completely avoid background signals. For example, in PCR-based LBA a single non-specifically bound DNA molecule is sufficient for generating a significant level of background. This background signal needs to be compensated by an increase in specific signals, which can be obtained by tailored SGR with increased affinity, such as antibody-DNA conjugates. ${ }^{66,72,73}$ Non-specific binding of SGR to endogenous components present in the biological matrix of the analyzed sample is a frequently encountered problem in LBA development. ${ }^{74-76}$ Importantly, the composition and complexity of the biological matrix often varies to a large extent from, e.g., species to species, between different study cohorts, healthy to diseased individuals, or even between samples drawn at different time points from one individual. Reduction of matrix effects is therefore of paramount importance to meet specificity and selectivity acceptance criteria. Specificity of the assay is related to cross reactivity of the used antibodies towards isoforms of the analyte or other structurally related targets present in the matrix. Specificity can be validated by spiking experiments using such interfering reagents if known and available. ${ }^{61,62}$ Selectivity is referred to as the ability of the assay to quantify the analytical target in the presence of other, unknown sample intrinsic components that may be specific for a certain subpopulation of the study or even disease related. Selectivity is validated in spiking experiments in multiple lots (usually 10 or more) per relevant sample matrix subpopulation (e.g. healthy $v s$. diseased) and specificity and selectivity are assessed for acceptable accuracy (\%RE) and precision $(\mathrm{CV} \%)$ in the majority of tested samples (usually $\geq 80 \%$ ). ${ }^{61}$

Negative influences of the biological matrix can be minimized by dilution of samples under optimized buffer 
conditions $^{45,49,66,77-79}$ because dilution affects low affinity interactions, i.e., the non-specific binding of assays reagents to matrix components, to a greater extent than the high-affinity interactions between the SGR and the target. Hence, sample dilution can lead to a significant increase in $\mathrm{S} / \mathrm{N}$ ratio, provided that the read-out of the assay is sufficient to generate clear signals even in the low concentration range. Moreover, dilution brings with it the opportunity to adjust buffer conditions with respect to $\mathrm{pH}$, ion strength, concentration of detergents and blocking reagents, or other factors which favorably affect the specific binding of SGR. ${ }^{80}$ The sample dilution ratio, optimized with respect to assay accuracy and precision using a specific diluent, is therefore often defined as "minimal required dilution (MRD)" of the bioanalytical method. ${ }^{61,62}$ Signal amplification-based ultra-sensitive LBA technologies, such as immuno-PCR (IPCR), allow for relative high sample dilution ratios while still maintaining the required sensitivity to support pharmacokinetic or pharmacodynamic studies (Fig. 3). ${ }^{77,81-85}$

LBA development and validation guidelines ${ }^{58-62}$ recommend that the standard curve matrix should be identical or as similar as possible to the study sample. This helps to compensate for effects interfering with antibody-analyte binding, because the matrix interference is synchronized between sample and standard curve performance. ${ }^{66,77}$ In the develop-

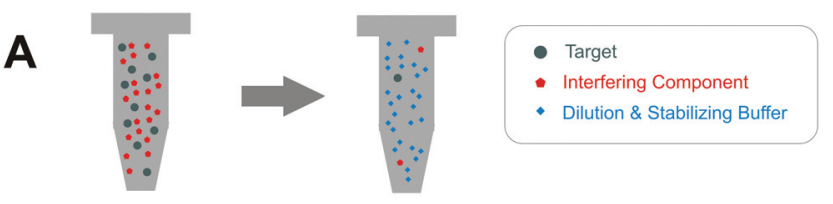

B

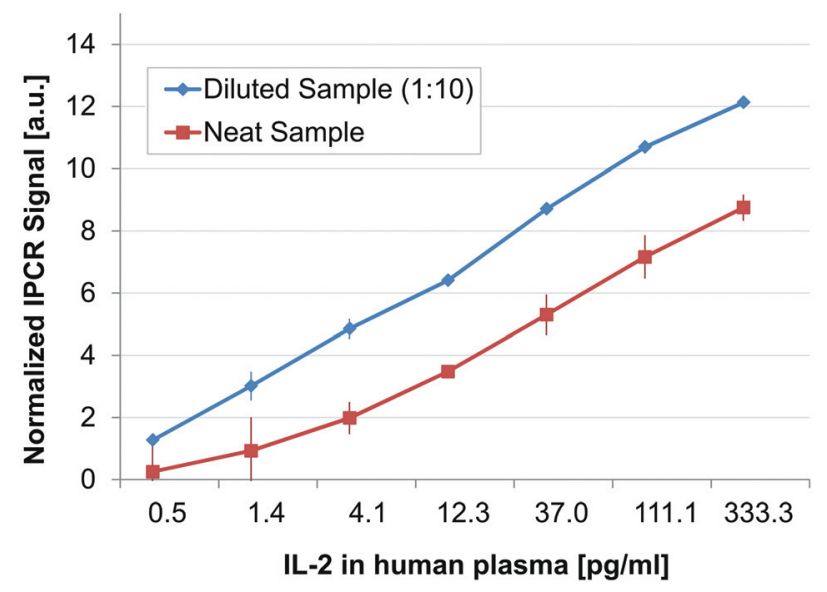

Fig. 3 The concentration of interfering matrix components in a test sample is reduced by dilution, as schematically depicted in (A). Sample dilution can lead to reduced negative matrix effects and improved analyte binding conditions, as exemplarily demonstrated in (B) for IPCRbased detection of human interleukin 2 (IL-2). Note that signal response is given in arbitrary units [a.u.] normalized by subtraction of non-spiked negative controls. The error bars indicate the standard deviation obtained from duplicate measurements. Data from ref. 86 . ment of PK methods to quantify exogenous drugs, quality control (QC) samples must be prepared with the same type of neat, unmodified matrix matching the study samples. ${ }^{61}$ In contrast, methods for assaying biomarkers ${ }^{62,63}$ can use standard curve matrices and QC samples prepared in a substitute matrix as long as this allows detection of the biomarker with adequate accuracy and precision. ${ }^{62}$ The reason for this recommendation is that endogenous biomarkers present in the standard-curve matrix will limit the sensitivity of the method, because SGR will specifically (!) bind to the endogenous marker in standards and QCs. Therefore, a standard matrix can be selected, which contains low concentrations of the biomarker, and this can be achieved, for instance, by stripping or immune-depletion of pooled samples, or even biomarker-free buffers.

\subsection{Sample information density}

Reduced sample consumption is of great importance in bioanalytical sample testing support where available amounts are of limited accessibility. This is the case in, e.g., small animal studies, orphan studies, lumbar punctures, biopsies, or even studies on the level of single cells. Macromolecule quantification in support of microsampling studies, i.e., dried blood spot sampling studies ${ }^{87}$ or studies restricted to very small sample volumes, ${ }^{88}$ which aim for generation of, e.g., complete PK-profiles from various time point blood samples derived from the tail vein of a single mouse, ${ }^{89}$ are becoming increasingly relevant. ${ }^{90}$ Obviously, it is desirable to extract as much information as possible out of a given amount of sample. While conventional ELISA testing typically requires approx. 50-100 $\mu \mathrm{l}$ sample volumes, amplification-based ultra-sensitive technologies often need volumes of $<5 \mu \mathrm{l}^{78,91}$ In addition to providing high sensitivity in LBA microsampling studies, toleration of high sample dilution also enables splitting of the sample into several fractions, which can then be analyzed individually to maximize the information density drawn from a single sample. This approach has been termed as "polyplexing" as a delineation to "multiplexing" where several analytical targets are detected simultaneously in a single experiment. Owing to spatially separated reactions, polyplexing avoids typical problems of multiplex analyses, which stem from promiscuous binding of SGR and non-specific cross-reaction between multiple critical assay reagents. Challenges regarding the selection of capture and detection antibodies increase exponentially with growing numbers of targets in multiplex assays. $^{92-94}$ Hence, the selection of highly target specific and non cross-reactive antibodies with comparable binding efficiencies are the major obstacles of multiplex immunoassays. In contrast, polyplexing has been demonstrated as a convenient strategy to avoid these problems because it combines economic sample consumption and maximization of the density of information which can be drawn from a single sample. ${ }^{81-84}$ 


\section{Ultra-sensitive ligand biding assay technologies}

Due to the high specificity of antibody-antigen binding, assays which employ antibodies as binding molecules play the major role among the ligand-binding assays, with ELISA $^{42,95}$ being the gold standard for large molecule pre-clinical and clinical bioanalytical sample testing support. In most ELISA variants, a detector antibody is used as SGR, which specifically binds to the target. Signal generation is usually achieved by an enzyme linked to the antibody, which converts a silent precursor molecule into a coloured, fluorescent or luminescent product in an amplified fashion (Fig. 4a). To discriminate specific signals from assay background originating from non-specifically bound SGR or autoconversion of the precursor molecule, antigen levels in the $\mathrm{pM}-\mu \mathrm{M}$ range are usually needed to become detectable at the macroscopic level. However, detection and quantification of molecular binding events is not limited to ELISA-type enzymatic signal generation. Alternative techniques based on chemical (ECL, Fig. 4b) or biochemical amplification reactions (IPCR, Fig. 4c) have been developed, which provide greater sensitivity than conventional ELISA methods. Moreover, high-sensitivity read-out of LBA can be achieved by techniques derived from single-molecule spectroscopy (single-molecule counting, SMC, see Fig. 5, below).

In this survey, we focus on methods, which are beyond the level of proof-of-concept studies and have already found their way into routine application, such that they have been evaluated in pre-clinical and clinical studies of pharmaceutical development. In particular, we will discuss amplified assays on the basis of electrochemiluminescence (ECL) or nucleic acid labels, i.e., IPCR, proximity ligation, and bead-based nucleic acid biobarcodes, along with amplification-free assays based on SMC. An overview of specific experimental details of these technologies is given in Table 1. Before in depth discussion of the aforementioned techniques along with related case studies, we note that ECL (chapter 3.2) can be considered the

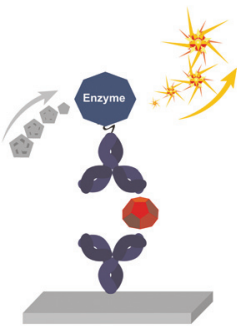

A: ELISA

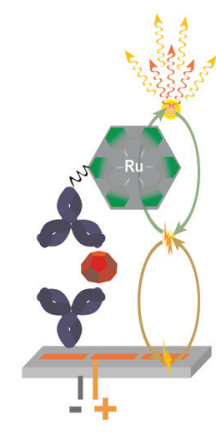

B: $E C L$

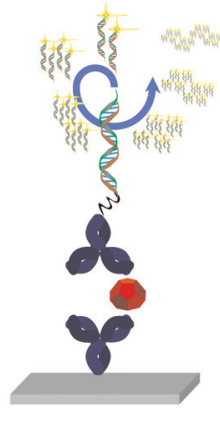

C: IPCR
Fig. 4 Schematic illustration of amplified LBA technologies, enzyme linked immune sorbent assay (ELISA), electrochemiluninescence (ECL), and Immuno-PCR (IPCR).

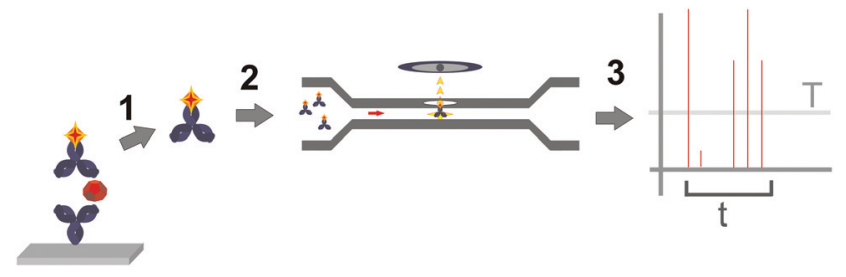

Fig. 5 Schematic illustration of single molecule counting (SMC) technology. 1: Solid-phase binding and separation of immunocomplex; 2: transfer to single-fluorescence detection cell and measurement; 3: analysis of signals above threshold " $T$ " in a given time " $t$ ".

most established high-sensitvity LBA technology in pharmaceutical drug development, with a mayor vendor offering commercial equipment and kits. This technique has already been reviewed extensively ${ }^{55,96-100}$ and we will therefore focus here on selected recent case studies. Nanoparticle-based "BioBarcode" technology (chapter 3.5) has also been reviewed recently ${ }^{91}$ with an emphasis on diagnostic applications. The fairly young technique of SMC (chapter 3.1) has so-far been predominantly used for diagnostic purposes with a strong focus on Troponin testing for cardiac infarction diagnosis. ${ }^{101}$ However, SMC is becoming more frequently used in pharmaceutically relevant sample testing support. ${ }^{57}$ Similar, IPCR is gaining an increased significance for pharmaceutical development processes (chapter 3.3), while the related nucleic acidenhanced proximity ligation currently appears to have an emphasis on biomarker discovery (chapter 3.4).

\subsection{Single-molecule counting}

Single molecule counting (SMC) represents an LBA which lacks any form of signal amplification but still holds the potential for increased sensitivity over standard ELISA. ${ }^{56}$ As outlined in Fig. 5, samples are diluted in assay buffer and the target molecule is allowed to bind to capture antibodies immobilized either in microtiter plates or on magnetic microparticles. The solid supports are washed and a fluorophore-labeled detection antibody is allowed to bind to the immobilized immunocomplex. Following to extensive washing to remove loosely bound detection reagents, immunocomplexes are disrupted with a protein denaturing elution buffer. The elution volume is typically considerably smaller than the initial sample volume, thereby increasing the concentration of the eluted fluorophore-labeled detection antibody. In the case of particlebased assay formats, samples are filtrated to remove particles for downstream signal read-out. The eluate is analyzed in a capillary flow cell through single molecule counting using an automated confocal laser microscope. Photons emitted from the fluorophore-labeled detection antibodies are counted in defined time intervals, automatically evaluated and plotted as individual peaks. These peaks represent digital yes/no information rather than signal intensity. The number of peaks per time interval allows one to calculate the concentration of fluorophore-labeled detection antibody, which is then used to 
Table 1 Overview of key aspects of the LBA technologies discussed in this review

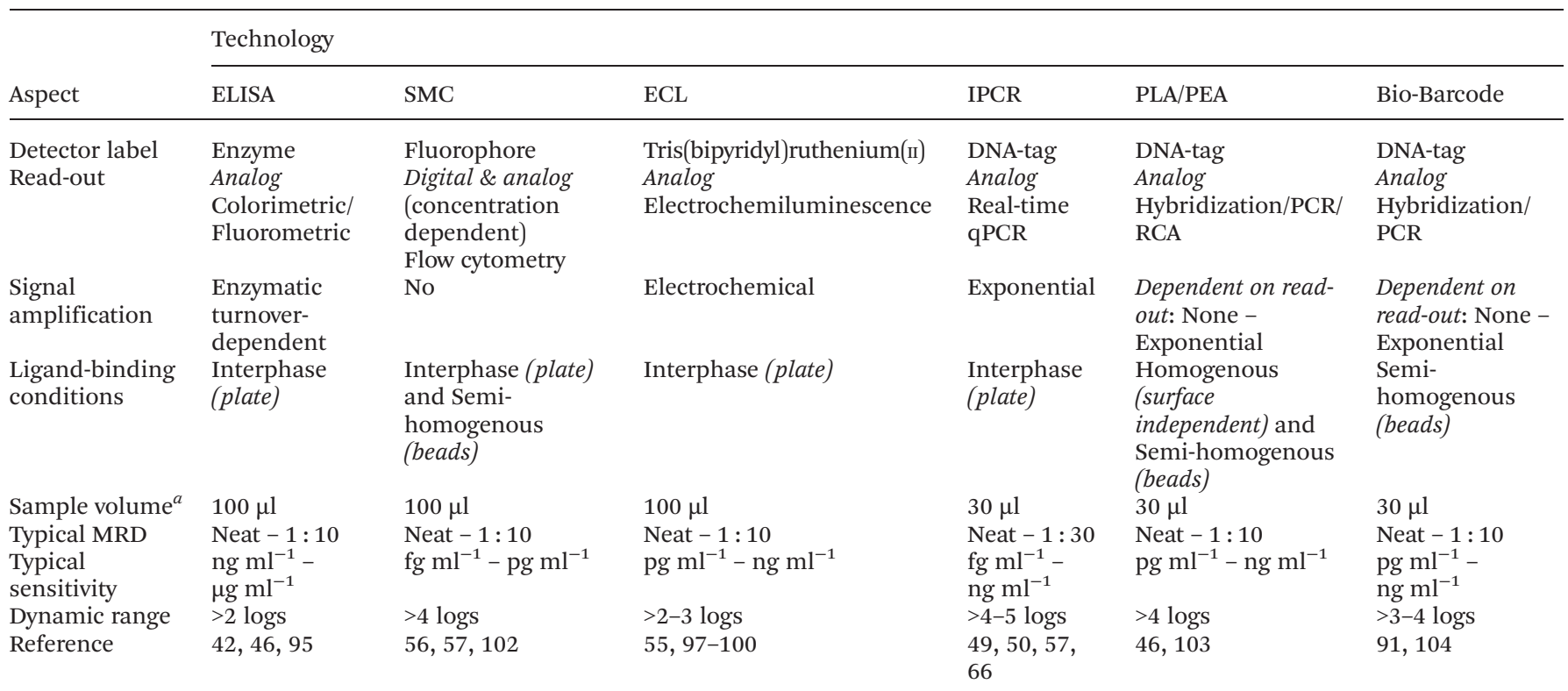

${ }^{a}$ Typical total per-well/vial volume at assay's sample dilution.

extrapolate the concentration of target antigen by aid of calibration curves.

SMC technology typically leads to impressive assay sensitivities and standard curve ranges. For instance, a greater than 4-log dynamic range from $60 \mathrm{pg} \mathrm{ml} \mathrm{m}^{-1}$ to $1 \mu \mathrm{g} \mathrm{ml} \mathrm{m}^{-1}$ was reported for detection of human Cytokine IL-17. ${ }^{56}$ Numerous publications relevant for pharmaceutical drug development, mainly regarding heart muscle biomarker Cardiac Tropo$\operatorname{nin}^{102,105}$ but also human cytokines, ${ }^{106}$ suggest that SMC is indeed emerging in pharmaceutical sample testing support. ${ }^{57}$ The fact that SMC immunoassays omit the need for enzymatic signal amplification is often considered as an advantage because no variations in enzymatic activity can occur which would bias the analysis. However, minor differences in enzymatic activity in amplification-based techniques, such as ELISA, ECL, or IPCR, are typically in an acceptable range. Likewise, variations in fluorophore-to-antibody labeling ratios, which may lead to differences in fluorescence read-out in SMC, seem to be controllable within the acceptable variations in accuracy and precision for pharmaceutical sample testing. ${ }^{58,60-62}$

However, the missing signal amplification step and the related demand for sufficiently high concentrations of analyteimmunocomplexes in the sample (or else, sufficient sample volumes to allow concentration of the analyte-immunocomplexes by solid phase-based techniques) can limit the scope of SMC. Sample dilution, which at the same time would reduce sample consumption, is not always possible because of the limited ability of SMC to tolerate higher sample dilution ratios needed for minimization of interference from matrix components (see section 2). These constraints can reduce options to adjust assay performance in pooled matrices necessary for analyzing individual samples from large patient cohorts, which bring with them all the individual effects that might show up in a clinical trial. ${ }^{61-63}$ Biological specimen often have to be filtered to ensure homogenous analyte-binding and filtration has to be validated with the assay to control any possible bias introduced by this step. Moreover, the extensive washing procedures needed to minimize signals from nonspecifically bound dye-labeled detection antibody as well as potential interference from autofluorescent matrix components and comparably long read-out time especially at low analyte concentrations to collect the needed signals constitute possible deficiencies of this technology.

It should be noted that additional amplification-free techniques are currently emerging, which promise applicability in real-life routine diagnostics and pharmaceutical sample testing. These approaches include cantilever array-based labelfree sensing, ${ }^{107-109}$ microscale thermophoresis, ${ }^{110}$ acoustic membrane micro particle (AMMP) technology, ${ }^{111}$ silicon photonic microring resonators ${ }^{112-114}$ or optical fiber bundles for single molecule detection and analysis. ${ }^{115-117}$ To the best of our knowledge, however, these techniques have not yet been exploited for routine support of pharmacological drug development studies.

\subsection{Electrochemiluminescence}

Electrochemiluminescence (ECL) of tris(bipyridyl)ruthenium(II) complexes is commonly used in immunoanalytics, clinical diagnostics and also pharmaceutical drug development. ${ }^{55,96-100}$ ECL works similar as the conventional ELISA, however, the signal amplification is facilitated by repeated oxidation and 
reduction of antibody-coupled tris(bipyridyl)ruthenium(II) complexes on electrode surfaces which leads to photon excitation upon regeneration with tripropylamine (Fig. 4b). ECL sensitivities are usually slightly better than those of conventional ELISA. The main advantage of this technology stems from its potential for multiplexed analysis of targets in unpurified sample materials without the need of extensive washing. ${ }^{118}$ Similar as in ELISA, specificity of critical assay reagents, in particular antibodies, and interference from matrix components with the analyte binding event drastically limit multiplexing capacity. With commercial vendors and contract research organizations (CRO) available, ECL is routinely used in pharmaceutical large molecule drug development support. Case studies range from oncology, ${ }^{119}$ neurodegenerative disorders ${ }^{120}$ and metabolic diseases ${ }^{121}$ to autoimmune defects. ${ }^{122}$ Moreover, ECL is widely used in screening for unwanted immunogenicity of Biologics. ${ }^{119,123}$ Some time ago, ECL support in drug development trials was hindered by the acquisition of the only commercial vendor which blocked the access to this technology by the acquiring party. ${ }^{124}$ These problems are nowadays solved and ECL is certainly a good alternative in cases where classical ELISA reaches it's limits.

\subsection{Immuno-PCR}

Since the early nineteen-eighties, the polymerase chain reaction (PCR) $)^{43,125}$ has become the major tool in molecular biology and the related life-sciences owing to the extremely sensitive and efficient amplification of nucleic acid templates. ${ }^{126}$ This level of sensitivity, nowadays routinely used for detection of even single molecular targets, ${ }^{127}$ has long been inaccessible for LBA technologies. To overcome these limitations, the concept of Immuno-PCR (IPCR, Fig. 4c), combining ELISA-type LBA technologies with the exponential signal amplification power of PCR, was developed in $1992 .{ }^{128}$ In contrast to the antibody-enzyme conjugates used in ELISA, the key reagents in IPCR are antibody-DNA conjugates wherein a DNA-marker is linked to the detection antibody. DNA-polymerase is added subsequently as part of a reaction master-mix, which allows for quantitative measurement of the DNA-marker (and thus the analyte-antibody immunocomplex) by quantitative PCR (qPCR). During the last two decades, an increasing number of DNA modifying enzymes and techniques for sequence specific manipulations of nucleic acids have led to additional DNA-based LBA technologies. Because these developments were typically conducted as proof-of-concept studies and they have been surveyed previously, ${ }^{45,47,51,52,129}$ we will here focus on the most important features of IPCR and illustrate the state-of-the-art of this LBA technology on the basis of case studies in the area of pharmaceutical drug development programs.

Even though amplification of nucleic acid molecules allows one for detection of theoretically single target molecules, the immune-affinity coupling steps between DNA-labeled detector molecules and analyte significantly increases the number of target molecules needed for specific signal amplification. Due to the steady-state on/off kinetic nature of antibody-antigen binding, a level of approx. 1000 analyte molecules in a typical immunoassay volume of $100 \mu \mathrm{l}$ can be considered as theoretical detection limit for immunoassays. ${ }^{130-132}$ The survey of LODs (limit of detection) reported in relevant IPCR publications confirmed this theoretical considerations. ${ }^{50}$ Indeed, a broad range of IPCR case studies demonstrated LODs close to the theoretical detection limit of LBAs, down to a few 1000 analyte molecules or even below. ${ }^{45-47,50,129}$ Applying these numbers onto a typical protein target of about $50-100 \mathrm{kD}$ in size, this LOD translates into sub-picogramm amounts of target proteins, which is considered sufficient for quantification of low abundant biomarkers or free bioactive markers traced in supportive (pre)clinical LBA support studies where the biomarker is the actual drug target. ${ }^{49}$

Various modifications of the initial IPCR protocol ${ }^{128}$ have been reported, many of which have led to a significant increase in the analytical sensitivity. In some academic and exploratory applications even an extreme enhancement of more than 100000 -fold in comparison to ELISA LODs was reported. ${ }^{133-136}$ Despite these impressive numbers, IPCR assays have long been considered as cumbersome, hard to develop, and lacking the robustness required for bioanalytical sample testing support in pharmaceutical drug development. Technical issues concerned the availability of appropriate microplate materials which are thermostable and have high protein binding capacity, ${ }^{49}$ as well as the need for careful handling of liquids and avoidance of plate transfer steps to minimize cross-contamination. ${ }^{137-139}$ These issues also apply for alternate approaches, such as bead-based IPCR assays ${ }^{49,91,140,141}$ or chemically activated glass surfaces designed for automated processing. ${ }^{142}$ Therefore, similar as for $\mathrm{SMC}^{56}$ or ECL, ${ }^{99}$ specialized laboratory equipment and matching kits of reagents and consumables are mandatory to take full advantage of the power of this LBA technique. ${ }^{126}$ For instance, highly sensitive quantitative Immuno-PCR (qIPCR) ${ }^{66}$ assays, commercially available since the early 2000 years, contain pre-synthesized antibody-DNA conjugates. These are the key reagents for IPCR because they eliminate cumbersome syntheses or multi-step on-surface assembly of immunocomplexes. ${ }^{49,50,91,143-145}$ The latter is particularly disadvantageous for assay performance because each coupling step in the LBA protocol represents a potential error source ${ }^{132,146,147}$ and leads to decrease in assay performance. ${ }^{64}$ These developments led to reduction of LLOQ for macromolecules in pharmacokinetic and pharmacodynamic pre-clinical ${ }^{81}$ and clinical studies $^{16,82,148,149}$ down to several 1000 molecules along with a wide standard-curve range of up to six orders of magnitude. ${ }^{45,47}$

As an example, the advantages of pre-conjugated reagents over sequential protocols have clearly been demonstrated in a study concerning detection of human interleukin 6 (IL-6). ${ }^{66}$ Indirect sandwich assay and sequential incubation resulted in an LOD of $10 \mathrm{pg} \mathrm{ml}^{-1}$ IL-6 in human serum, demonstrating an approx. 100-fold improvement over conventional ELISA. In comparison, the use of IL- 6 specific pre-conjugated reagents 
enabled another 100-fold gain in sensitivity with an LOD of $100 \mathrm{fg} \mathrm{ml}^{-1}$ corresponding to an approx. 10 000-fold advance as compared to ELISA. ${ }^{66}$ Commercial IPCR technology is nowadays available at contract research organizations (CRO) ${ }^{150,151}$ for custom assay development ${ }^{83,84,151-153}$ as well as bioanalytical services under various regulatory regimes up to full good laboratory practice (GLP) standards. ${ }^{57,150,154}$ This not only enables pre-clinical toxicology studies to support investigational new drug (IND) programs but also to realize fully validated IPCR protocols for sample testing support under GLP regime. It is therefore not surprising that this technology has found its way into routine application. Exemplary case studies will be discussed in the following.

Mucosal vaccination. IPCR has a proven track record in the quantification of viral loads enabling valuable information on the acute status of a viral infection. Examples include HIV, ${ }^{155}$ rotavirus $^{78}$ and norovirus, ${ }^{156}$ wherein highly complex and challenging matrices like food homogenate or patient stool underlined the method's high matrix tolerance. Likewise, very low numbers of pathogens were detected in large sample volumes, e.g., to monitor bacterial contamination of water ${ }^{157}$ and food. ${ }^{158-162}$ Moreover, single-cell sensitivity was demonstrated in pre-implantation diagnostics of histocompatibility complexpresenting blastocysts. ${ }^{163,164}$ Based on this capability for the high-sensitivity quantification of biomarkers, IPCR has been used in the development of novel vaccination strategies. ${ }^{165-167}$ Virosomes are artificial virus particles presenting the actual vaccine structure but lacking the viral genome. Virosome vaccination against mucosal transfected diseases, such as HIV, was recently established by aid of IPCR as supportive analytical technique in the course of an initial phase-I clinical trial. ${ }^{82,83}$ In this study, anti-vaccine specific IgA and IgG antibodies as well as total IgA and IgG response needed to be quantified in mucosal and serum samples (Fig. 6). Particular challenges included the approx. 100-fold lower antibody concentrations in mucosal tissue as compared to blood as well as strongly limited mucosal material owing to the complex mucosal sampling procedures. Moreover, it was difficult to identify antibodies for specific differentiation of the four immunoglobulin targets in the presence of cross-reactive alternate immunoglobulin subspecies present in the samples. The use of high sample dilution of up to 1:1000000 solved these problems. Four antibody concentrations could be quantified in parallel from the limited mucosal material and serum samples, using the polyplexing strategy. Hence, this case study underlines a general and highly important feature of the IPCR technology: although multiplexing of IPCR assays has proven feasible, ${ }^{49,65,68,168,169}$ high sample dilution along with polyplexing leads to better results because the employed antibodies cannot cross-react with each other.

Biomarker quantification. Quantification of biomarkers for exploratory purposes or bioanalytical support in pharmacodynamics $(\mathrm{PD})^{170}$ represents an important field where highsensitivity IPCR assays are applied. ${ }^{49,50}$ For example, relevant biomarkers for neurodegenerative disorders like Alzheimer's and Parkinson's disease or vCJD typically are found in the
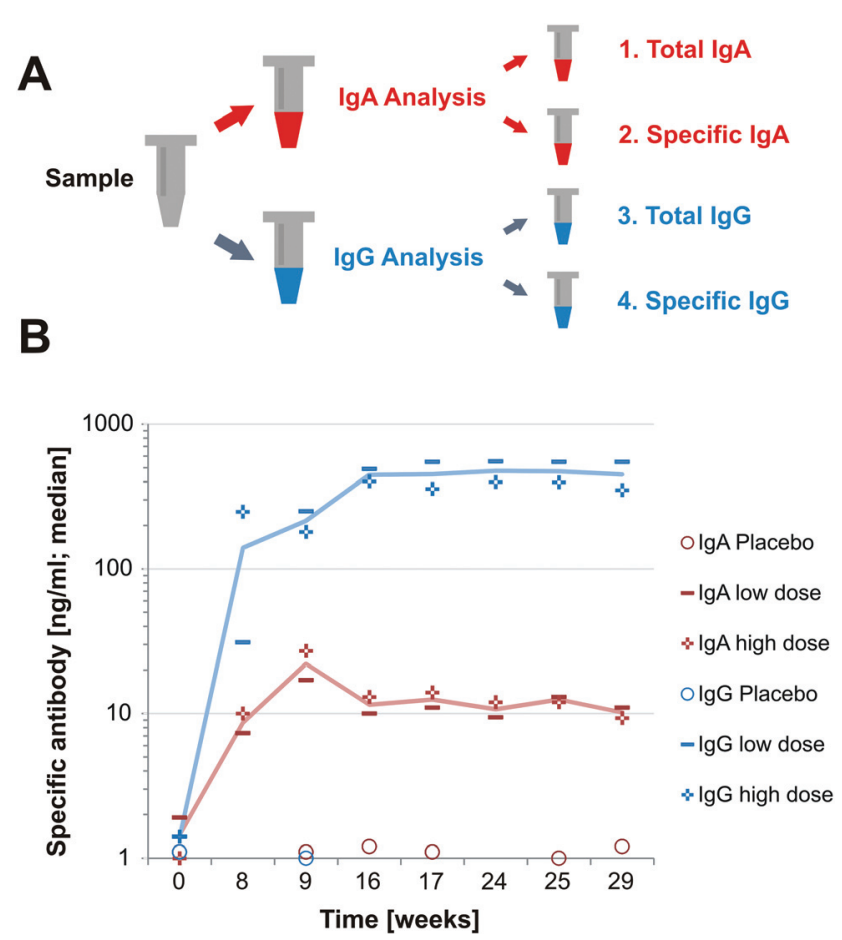

Fig. 6 A.) Scheme on polyplexing strategy for IPCR sample testing to support a clinical phase I Virosome HIV vaccination trial in young healthy women. ${ }^{82,83}$ High sample dilution in IPCR allows to divide a single mucosal or serum sample for separate quantification of Virosome specific $\lg A$ and $\lg G$ response in addition to total $\lg A$ and $\lg G$ levels. This allows for normalization of specific response for variability in mucosal sampling and overall immune status. b.) High (+) and low (-) dosed vaccination leads to specific IgA and IgG response, clearly detectable over the corresponding placebo (o) groups. The solid lines represent the median from high $(+)$ and low $(-)$ dosed antibody response. No unspecific cross reactivity in testing for specific vs. total antibody was found, despite the fact that a greater than 1000 -fold excess of total over specific antibody was present in the samples. ${ }^{83}$

brain at very low concentration in early development phases of these diseases. ${ }^{171}$ The analysis of sample materials from invasive procedures like lumbar puncture or cerebrospinal fluid (CSF) drawn directly from the brain for in vivo/ante-mortem detection requires a bioanalytical method with minimal sample consumption and matrix interference and yet an excellent sensitivity. ${ }^{172}$ Moreover, detection of indicative biomarkers in the periphery, such as blood, would be highly attractive due to easier accessibility of samples, but biomarker concentrations in blood are drastically lower than in the central nervous system. ${ }^{173}$ Owing to it's extraordinary sensitivity, IPCR has successfully been applied for quantification of neurodegenerative disease biomarkers in various matrices. One case study concerned the analysis of a phosphorylated TAU protein biomarker associated with Alzheimer's disease, pTAU-Thr ${ }_{181},{ }^{174,175}$ In the course of a pre-clinical study support, this biomarker was quantified in murine CSF microsamples because the total CSF volume available from a single sacrificed mouse is only approximately $5 \mu \mathrm{l} .{ }^{176}$ IPCR provided 
a meaningful sensitivity of around $1 \mathrm{pg} \mathrm{ml}^{-1}$ LLOQ at $1 \mu \mathrm{l}$ sample requirement for testing in duplicate. Other examples of IPCR for biomarker quantification from microsample materials obtained by non- or less-invasive procedures (e.g. fingertip/earlap blood $v s$. venous blood, or venous blood $v s$. biopsy) include various metabolic intermediates. ${ }^{4,50}$ For instance, the pharmacological relevant biomarkers myostatin propeptide and follistatin, correlated to fat and muscle metabolism, ${ }^{177,178}$ were quantified in earlap blood-derived serum and muscle biopsy human samples to identify characteristic patterns indicative for doping effects in sports. ${ }^{169}$

Cytokines represent an important class of pharmaceutically relevant biomarkers because not only they are often used to monitor effects of therapeutic drugs but also because they are often the actual drug target for treatment of disease indications, such as autoimmune disorders. Examples for IPCRbased analyses of such biomarkers important for cell growth, differentiation, and immunomodulation include IL-6, ${ }^{66}$ IL-18 ${ }^{179}$ and TNF. ${ }^{139,180-182}$ Another member of the cytokine panel is human Granulocyte Macrophage Colony Stimulating Factor (GM-CSF), ${ }^{144,183,184}$ which is secreted by various celltypes of the immune system and, among other activities, believed to play a major role in the development of autoimmune inflammatory diseases like multiple sclerosis, and rheumatoid arthritis, and respiratory defects like atopic asthma. ${ }^{143}$ Therefore, GM-CSF is often used as indicative biomarker for the development of novel drug candidates, ${ }^{143,144}$ and recombinant GM-CSF is applied as immune modulating drug. ${ }^{145,185}$ Since endogenous GM-CSF levels are usually low, ultra-sensitive bioanalytical support was enabled by a validated IPCR assay, which enabled the quantification of changes in endogenous GM-CSF concentrations in the range of 0.01-200 $\mathrm{pg} \mathrm{ml}{ }^{-1}$, with an LLOQ of $11 \mathrm{fg} \mathrm{ml}^{-1} \cdot{ }^{153}$ This assay indicated that endogenous levels of human GM-CSF were typically between $0.06-0.4 \mathrm{pg} \mathrm{ml^{-1 }}$ within the healthy control population, while asthma and multiple sclerosis patients have elevated levels in the range of $1.0-3.4 \mathrm{pg} \mathrm{ml}^{-1}$ and $1.6-4.4 \mathrm{pg} \mathrm{ml}^{-1}$, respectively. Notably, all these examples confirmed the broad dynamic range of IPCR assays, spanning at least four orders of magnitude.

Drug quantification and pharmacokinetics. ELISA assays are often sufficient for sample testing to determine drug concentration data in pharmacokinetic (PK) studies, ${ }^{186}$ because the drug is usually administered in relatively high dosage, leading to intracorporeal concentrations in the $\mathrm{ng} \mathrm{ml}{ }^{-1}$ range and above. ${ }^{187,188}$ However, determination of PK profiles for some drug candidates, like highly cytostatic drugs ${ }^{77,149}$ or potent toxin derivates ${ }^{189}$ require low dosage and thus ultrasensitive bioanalytical support. As an example, the picomolar potency of ShK-186, ${ }^{190}$ a venom peptide derived from sea anemone, demanded ultra-sensitive bioanalytical sample testing support to characterize the pharmacokinetic profile of the drug in a clinical phase-I trial. ${ }^{191}$ This highly toxic peptide is a specific and potent inhibitor of the Kv1.3 ion-channel and suppresses activation of TEM cells leading to a reduction of inflammation and tissue damage. Hence, ShK-186 is under development for treatment of various autoimmune diseases. A highly sensitive IPCR assay was developed and validated in accordance to relevant industry guidelines to quantify low pg $\mathrm{ml}^{-1}$ concentrations of ShK-186 for clinical sample testing support. ${ }^{152}$ Previously evaluated technologies indicated very low PK concentrations in animal toxicology studies, even with administered dosages of up to 500-fold above the effective dose. Therefore, phase-I trial support required quantification of concentrations of down to 250-fold lower than the concentrations administered in the toxicology studies. The developed IPCR assay offered a more than 135- or 650-fold increased sensitivity as compared to the corresponding LC-MS or ELISA assays, respectively. It was therefore suitable for supporting the clinical trial, which included single ascending doses in healthy subjects with four dosing cohorts. In the blinded sample panel it was possible to correctly identify the unknown placebo individuals through specific PK profiles, revealing details like the maximum drug concentration recorded $\left(C_{\max }\right),{ }^{192}$ the time interval to reach maximum drug concentration $\left(T_{\max }\right){ }^{192}$ andspecific profiles of drug wash-out phases. This not only allowed the prediction of the therapeutic range but also shed light on previously observed but not well understood PD effects. Connection with PK data then enabled modelling $\mathrm{PK} / \mathrm{PD}$ correlation to establish optimized dosing protocols for future trials. ${ }^{152}$ This case study nicely demonstrates how ultra-sensitive PK support fosters the development of novel extremely potent drug classes, such as toxin-like peptides.

IPCR has also been employed to compensate for strong matrix effects or the presence of endogenous compounds, which interfere with the quantification of the drug. Many biotherapeutic drug candidates, which possess structurally homologous domains to the endogenous protein ${ }^{5,8,9}$ or fusionproteins $^{193}$ are prone to competitive interaction with their endogenous binding partners, present in clinical study samples. This leads to a decrease in effectively detectable drug concentration due to limited binding capacity of the capture coated surface in ELISA-type LBA, and thus calls for ultra-sensitive techniques. In a recently published case study, IPCR was employed for PK sample testing of a novel biotherapeutic Fcfusion protein, ${ }^{193}$ under development as a drug for a novel long-acting replacement therapy. ${ }^{84}$ Bioanalytical support of phase-II/III studies for this replacement therapy required an LBA with minimal interference of the endogenous counterpart and circulating IgG. It was found that an IPCR assay had sufficient analytical sensitivity despite the high MRD of $1: 100$ of the clinical sample, chosen to minimize interference from endogenous binding partners. The assay was fully validated to meet clinical sample testing support requirements and provided a dynamic range of $20-9000 \mathrm{ng} \mathrm{ml}^{-1}$ of the recombinant Fc drug with no significant interference from a greater than 300000 -fold excess of endogenous IgG as well as the endogenous specific binding partner present in $>250$-fold excess. Assay parameters met validation criteria in human plasma, either depleted or deficient of the endogenous counterpart, as well as normal human plasma, using depleted human plasma pool 
as standard-curve matrix. Dilution integrity and linearity was confirmed, thereby allowing for further sample dilution, which led to the expansion of the detection range to up to $50000 \mathrm{ng}$ $\mathrm{ml}^{-1}$. Since this method was successfully used for bioanalytical support of a clinical phase-II/III multi-center study, this case study impressively demonstrates the utility of IPCR for PK support of testing novel pharmaceutical large molecule drugs.

The testing for unwanted immune response of patients exposed to Biologics is a task related to PK assessment of this class of drugs. Immunogenicity of the drug may have various consequences ranging from affecting the PK profile over mild or severe adverse reactions up to an anaphylactic shock. ${ }^{33}$ The use of IPCR for immunogenicity testing has been described to reveal a good tolerance towards the presence of circulating drug in the sample, which blocks the anti-drug antibody (ADA) from binding to the drug. ${ }^{85}$ To this end, the drug is employed as binding reagent in the so called bridging assay format. In this example, the sensitivity of IPCR was exploited to detect free ADA present in the sample despite a significant excess of the interfering drug, thereby demonstrating an optimized drug tolerance of this assay as compared to ELISA or ECL. ${ }^{194,195}$ Depending on the sensitivity for the ADA, binding affinity of the employed ADA standard to the drug and other study specifics, IPCR assays can be designed with ${ }^{195}$ or without ${ }^{194}$ acid dissociation steps, routinely employed in alternate LBA techniques to liberate ADA from the circulating drug.

\subsection{Proximity ligation}

Similar as in IPCR, a number of additional commercially available LBA technologies make use of nucleic acids as markers for enzymatic signal amplification and read-out. While the majority of these LBA employs capture reagents on solid phase supports either in microtiterplates or in suspension assays using micro- and nanoscaled beads, homogenous assay formats can also be used. The latter have the advantage of more efficient analyte binding because binding is less affected by mass transport phenomena at the interphase and thus binding equilibria are reached faster than in heterogeneous assays. Since no washing steps can be implemented in homogenous assays, they also come along with shorter processing times. Primary examples of sensitive homogenous solution assays are proximity ligation assays (PLA), ${ }^{46,196,197}$ which have been reviewed recently. ${ }^{51}$ In PLA, two specific antibodies directed against the target are labelled with individual oligonucleotides. Coincident binding of the two antibodies enables enzymatic ligation of the two oligonucleotides in the presence of a supporting third DNA oligonucleotide to generate a DNA template molecule for subsequent PCR or rolling circle amplification (RCA) (Fig. 7). The Nucleic Acid Detection ImmunoAssay (NADIA) ${ }^{198}$ technique, a variant of PLA also referred to as proximity extension assay (PEA), ${ }^{199}$ omits enzymatic ligation of the two marker-oligomers and, instead, uses self-priming overhang sequences of the two detector oligomers to enable primer extension with a polymerase leading to formation of a double-stranded template for subsequent PCR signal amplification. Usually, either polyclonal antibodies or two mono- clonal antibodies binding different epitopes of the analyte are used to realize liquid phase binding in PLA or NADIA. ${ }^{197,200-202}$ These technologies have been proven especially useful for quantitative assessment of ligand/receptor interactions and conformatorial changes in analyte structure. ${ }^{196,203}$ Spatial proximity of epitopes present in either one or else interacting pharmaceutically relevant biomolecules can be quantified through signal amplification of the assembled DNA-marker. ${ }^{197,198,201}$

PLA critically depends on the selection of specific antibody pairs, required to simultaneously bind the analyte in a way that enables enzymatic ligation or primer extension. A polyclonal antibody population directed against a given antigen can be used for this purpose, which is split into two fractions each including binders for different epitopes which are labelled with one of the two DNA marker strands. ${ }^{204}$ Even though this strategy proved feasible for the detection of protein biomarkers with femtomolar sensitivity, ${ }^{204}$ the variability of polyclonal antibody preparations brings the drawback of limited longterm availability of critical assay reagents in routine applications. In particular, even slight variations in polyclonal antibody properties can strongly affect assay reproducibility in support of larger clinical trials. The concept of solid-phase PLA (spPLA) ${ }^{205,206}$ using an additional capture antibody immobilized on magnetic particles along with the two oligo-

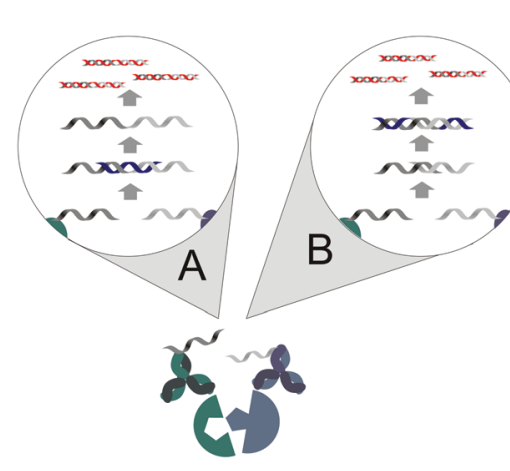
Homogenous Assay
A: Proximity Ligation (PLA)
B: NADIA

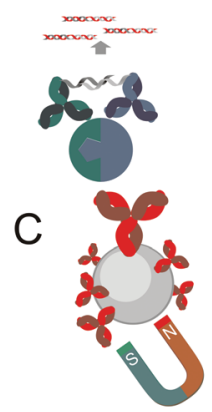

Semi-Homogenous
Assay

(spPLA on Magnetic Beads)
Fig. 7 Schematic overview on proximity assays. Separate DNA-tags of at least two different antibodies binding to epitopes in close proximity are used to generate a specific signal for the immune-binding event. Homogenous assay formats: (A) Proximity Ligation Assay (PLA). The fulllength DNA template for downstream signal amplification by PCR is generated by ligation of two DNA oligonucleotides in the presence of a short DNA connector sequence ("splint"). (B) Nucleic Acid Detection ImmunoAssay (NADIA)/Proximity Extension Assay (PEA). Two selfpriming overhand sequences enable primer extension by DNA-polymerase to enable subsequent signal amplification by PCR. C) Semi-homogenous solid phase Proximity Ligation Assay (spPLA). The two DNAtagged detection antibodies are supplemented with a third capture antibody, immobilized on the surface of a magnetic bead. In comparison to homogenous assay formats, this approach can lead to increased assay specificity and selectivity due to the third independent antibody binding event and the possibility for additional washing and sample processing steps. 
nucleotide-labeled antibodies for signal generation (PLA probes) gives rise to effectively screen for suitable antibody combinations. The three independent binding events even more increase the specificity of detection. Furthermore, spPLA allows one to include washing steps for removal of excess PLA probes. ${ }^{205}$ In an impressive proof-of-concept study, a variant of spPLA, dubbed ProteinSeq, which employed PCR-based amplification along with next generation sequencing $(\mathrm{NGS})^{207-209}$ as read-out, was used for highly multiplexed protein biomarker screening to simultaneously detect 35 human biomarkers in a volume of only $5 \mu \mathrm{l}$ of plasma sample. ${ }^{103}$ Interestingly, no molecular weight-dependent bias in assay performance was reported for targets down to $17 \mathrm{kDa}$, even though three independent epitope-binding events are necessary to obtain signals.

Another key requirement of pharmaceutical testing support concerns assay precision, which has been reported as unacceptably high for PLA in the case of real-time PCR readout. ${ }^{205}$ So called "digital PLA" has been developed to optimize PLA assay precision. ${ }^{210}$ It combines single molecule counting, referred to as amplified single molecule detection (ASMD) $)^{211}$ and SpPLA, ${ }^{205,206}$ and improved precision has been claimed for this rather complex procedure although no specific data on improved intra- or inter-assay precision were reported. ${ }^{210}$ Nonetheless, PLA and related techniques certainly hold great potential for use in pharmaceutically relevant application fields like oncology ${ }^{212}$ immunology ${ }^{213}$ neurodegenerative disorders, ${ }^{214}$ virology ${ }^{215}$ or stem cell research. ${ }^{216}$ Examples from these fields include analysis of gene expression, ${ }^{217-221}$ the study of post-translational modifications or gene splicing, ${ }^{197,222,223}$ the monitoring of conformational changes in protein structure, or quantification of protein-protein interactions. ${ }^{196,201,202,224-227}$

In a phase-I clinical gene therapy trial published recently, ${ }^{228}$ PLA was used to analyze changes in tumor suppressor gene (TUSC2) protein expression in biopsy samples of three lung cancer patients. Lack of TUSC2 activity is correlated with development of lung cancer and TUSC2 expression plasmid-containing nanoparticles were administered intravenously to reactivate TUSC2 activity in primary and metastatic tumors. Rabbit polyclonal antibodies directed towards the amino-terminal sequence of the TUSC2 was used and a 10-25fold increase over background levels prior to treatment could be demonstrated with the PLA assay. Another case study has also been reported where PLA has been used in support of gene therapy using a modified adenovirus. ${ }^{229}$

Owing to the afore mentioned possibilities to combine sensitivity with specificity in highly multiplexed protein detection, the most promising pharmaceutically relevant application of PLA and related techniques appears to concern the identification and validation of novel biomarkers for use in translational medicine. ${ }^{230}$ Numerous reports on highly multiplexed biomarker screening, ${ }^{200,204,231,232}$ especially in human blood proteome ${ }^{199,205,233,234}$ have been published in the last 15 years. ${ }^{235}$ Despite this vast number of biomarker candidates, on average, less than two per year were actually approved by the
FDA. $^{236}$ This underlines the relevance of PLA, spPLA and related techniques to overcome and extend the limitations of conventional multiplex immunoassays, which often do not provide the necessary specificity to unambiguously identify a relevant biomarker. Moreover a significant increase in capacity from a handful of targets in conventional LBAs to hundreds or even several thousands of targets is in sight by using homogenous or "ProteinSeq" ${ }^{\text {"103 }}$ PLA-type approaches. While conventional immunoassays are prone to wrong positives in the identification of lead biomarkers due to cross reactivity of the used antibodies, this effect seems to be controllable with PLAtype techniques. ${ }^{231,235}$ This would hold great potential for translational medicine, in the identification and exploitation of pharmaceutical relevant molecular interactions. ${ }^{237}$

\subsection{Nanoparticle-based methods}

The so-called "Bio-Barcode" approach, ${ }^{91,104,136,238-240}$ takes advantage of micro- and nanoparticles. Capture antibodycoated magnetic microparticles and gold nanoparticles functionalized with both detector antibody and marker-DNA molecules $^{241}$ are used for detection of protein targets. ${ }^{46,47}$ As schematically illustrated in Fig. 8, the capture antibody-coated magnetic microbeads are used for concentration of soluble antigens on the bead's surface and subsequently, gold nanoparticles ${ }^{242-244}$ bearing amplifyable DNA marker molecules (the bio-barcodes) and analyte-specific detection antibodies are allowed to bind to the analyte-containing

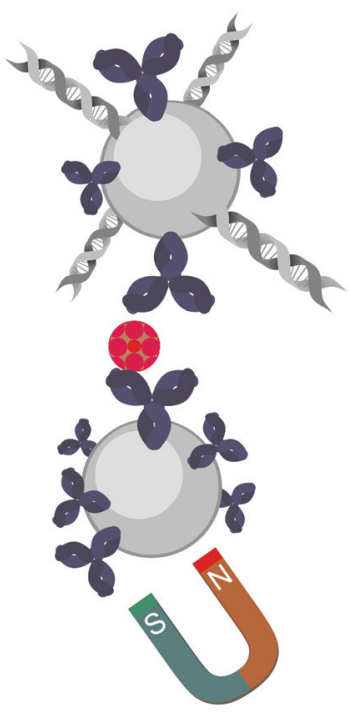

\section{Bio-Barcode}

Fig. 8 Bio-Barcode technology. Magnetic microparticles containing capture antibodies are used for enrichment of target (red sphere) and, following magnetoseparation and washing, gold nanoparticles functionalized with detection antibodies and DNA reporter molecules, the "Bio-Barcodes", are bound. Subsequent to magnetoseparation and washing, immunocomplexes are dissociated and detection of DNA reporters is achieved by hybridization or PCR. 
microparticles. Immunocomplexes are purified by magnetic separation and the bio-barcode sequence is detected by either hybridization ${ }^{239,240,245}$ or qPCR. ${ }^{91,246}$ Although no case studies using "Bio-Barcode" approaches for PK sample testing support are available, pharmaceutically relevant case studies range from quantification of toxins, ${ }^{247,248}$ food-born ${ }^{249}$ and other human pathogens ${ }^{250-252}$ over HIV $^{253,254}$ and other viruses ${ }^{255,256}$ to human biomarkers like cytokines, ${ }^{240} \mathrm{PSA},{ }^{257}$ thrombin,${ }^{258}$ or cytochrome c. ${ }^{259,260}$

\section{Conclusions}

The increasing developments of "Biologics", novel protein therapeutics for treatment of complex human disease indications, which are out of reach of traditional small molecule drugs, has led to the emergence of novel ligand binding assay (LBA) tools to meet the challenges in the corresponding bioanalytical sample testing within pre-clinical, clinical and even post-marketing studies. Quantification of protein therapeutics or biomarker levels in clinical samples is extremely important for diagnosis and prognosis of many diseases, optimization of dosages or evaluation of drug efficacy. Since the determination of drug or biomarker concentrations directly at the site of their action (e.g., organ tissue) is often not possible, serological samples, serum or plasma, are used as surrogate matrix in the majority of clinical studies. Therefore, circulating analyte concentrations can be very low. In addition, endogenous levels of relevant biomarkers are frequently below detection limits of conventional ELISA techniques, which have been the traditional workhorse in immunoanalytics and can still be considered the gold standard. Consequently, immunoassays have constantly been improved in performance regarding their sensitivity and dynamic detection range. The elaboration of alternative signal amplification methods, in particular electrochemiluminescence, nucleic-acid tags enabling PCR read-out, or bead-based methods, even coupled with single molecule detection, has led to improved immunoassay sensitivities by several orders of magnitude. The emerging LBA technologies discussed here represent the current state-of-the-art in ultrasensitive methods for pharmaceutical drug testing support. The survey of case studies employing either one of these methods suggests that no one-method-suits-all-applications is currently available because the different LBA technologies have their specific advantages to meet the needs of a given study. For instance, technologies with limited or no signal amplification, like single molecule counting, have the advantage that signal read-out cannot be biased by any kind of enzymatic signal amplification, which might be influenced by matrix components, for example phosphatase or peroxidase inhibitors. Proximity-based assays, like PLA, can be employed to almost entirely suppress non-specific signals, even in highly multiplexed assay formats. This provides a well suited platform for biomarker identification or validation, which may potentially revolutionize the identification and selection of biomarkers or lead compounds for drug development. However, these platforms do not always display highest sensitivity, which is typically needed when it comes to downstream analyte quantification, in particular, from small sample volumes. In these cases, PCR-based LBA platforms, such as IPCR, seem to be the best choice because of their enormous strength in signal amplification. This brings with it an excellent tolerance for high sample dilution ratios, which even allow for improvement of assay sensitivities. Highest amplification power sets the basis for successful immunoassay sample testing in so-called microsampling ${ }^{88,89}$ studies, where very small sample volumes are available due to time-course studies in individual, small animal models or because sampling stress to patients needs to be minimized. For example, this is the case in Dried Blood Spot (DBS) $)^{87,261,262}$ sampling studies, which allow patients to collect minimal invasive blood samples on specific filter paper at their homes rather than undertaking venous blood sampling during frequent hospital visits. In general, strong signal amplification opens the door to flexible assay adaptation by sample dilution protocols to meet the requirements when the bioanalytical sample testing support has to progress with the drug development trial. The here discussed ultra-sensitive LBA platforms provide a sound basis for further coevolution along with the progression of lead compounds in the development of modern drugs to improve the quality of patients lives.

\section{References}

1 B. Gorovits, S. C. Alley, S. Bilic, B. Booth, S. Kaur, P. Oldfield, S. Purushothama, C. Rao, S. Shord and P. Siguenza, Bioanalysis, 2013, 5, 997-1006.

2 B. A. Teicher and R. V. Chari, Clin. Cancer Res., 2011, 17, 6389-6397.

3 D. J. Crommelin, G. Storm, R. Verrijk, L. de Leede, W. Jiskoot and W. E. Hennink, Int. J. Pharm., 2003, 266, 3-16.

4 J. M. Reichert and C. Paquette, Curr. Opin. Mol. Ther., 2003, 5, 139-147.

5 H. Schellekens, NDT Plus, 2009, 2, i27-i36.

6 G. Walsh, Nat. Biotechnol., 2003, 21, 865-870.

7 G. Walsh, Trends Biotechnol., 2005, 23, 553-558.

8 L. Amaravadi and J. Marini, Bioanalysis, 2013, 5, 515-516.

9 P. Oldfield, Bioanalysis, 2013, 5, 533-535.

10 C. A. Bentley, O. A. Bazirgan, J. J. Graziano, E. M. Holmes and V. V. Smider, Methods, 2013, 60, 91-98.

11 U. J. Seidel, P. Schlegel and P. Lang, Front. Immunol., 2013, 4, 76.

12 Z. Xu, H. M. Davis and H. Zhou, Pharmacol. Ther., 2013, 137, 225-247.

13 A. Beck and J. M. Reichert, $m A b s, 2013,5,621-623$.

14 P. J. Declerck, Expert Opin. Biol. Ther., 2013, 13, 153156.

15 J. S. Powell, N. C. Josephson, D. Quon, M. V. Ragni, G. Cheng, E. Li, H. Jiang, L. Li, J. A. Dumont, J. Goyal, 
X. Zhang, J. Sommer, J. McCue, M. Barbetti, A. Luk and G. F. Pierce, Blood, 2012, 119, 3031-3037.

16 A. D. Shapiro, M. V. Ragni, L. A. Valentino, N. S. Key, N. C. Josephson, J. S. Powell, G. Cheng, A. R. Thompson, J. Goyal, K. L. Tubridy, R. T. Peters, J. A. Dumont, D. Euwart, L. Li, B. Hallen, P. Gozzi, A. J. Bitonti, H. Jiang, A. Luk and G. F. Pierce, Blood, 2012, 119, 666-672.

17 Y. Hu, X. Guan, L. Fan, M. Li, Y. Liao, Z. Nie and L. Jin, J. Headache Pain, 2013, 14, 72.

18 L. Heinemann and D. Owens, J. Diabetes Sci. Technol., 2013, 7, 806-807.

19 J. Guan, S. Mathai, H. P. Liang and A. J. Gunn, Recent Pat. CNS Drug Discovery, 2013, 8, 142-160.

20 A. van Nieuwenhuijze, M. Koenders, D. Roeleveld, M. A. Sleeman, W. van den Berg and I. P. Wicks, Mol. Immunol., 2013, 56, 675-682.

21 I. Abraham, S. Tharmarajah and K. MacDonald, Expert Opin. Drug Safety, 2013, 12, 235-246.

22 A. Publicover, D. S. Richardson, A. Davies, K. S. Hill, C. Hurlock, D. Hutchins, M. W. Jenner, P. W. Johnson, J. Lamb, H. Launders, N. McKeag, J. Newman and K. H. Orchard, Br. J. Haematol., 2013, 162, 107-111.

23 N. Yafour, M. Brahimi, S. Osmani, A. Arabi, R. Bouhass and M. A. Bekadja, Transfusion clinique et biologique, 2013, 20, 5-6.

24 G. M. Barton, J. Clin. Inves., 2008, 118, 413-420.

25 R. V. D’Elia, K. Harrison, P. C. Oyston, R. A. Lukaszewski and G. C. Clark, Clin. Vaccine Immunol., 2013, 20, 319-327.

26 N. Sachdeva and D. Asthana, Front. Biosci., 2007, 12, 4682-4695.

27 C. Knox, V. Law, T. Jewison, P. Liu, S. Ly, A. Frolkis, A. Pon, K. Banco, C. Mak, V. Neveu, Y. Djoumbou, R. Eisner, A. C. Guo and D. S. Wishart, Nucleic Acids Res., 2011, 39, D1035-D1041.

28 K. McKeage, Drugs, 2013, 73, 195-206.

29 R. K. Aggarwal and R. Showkathali, Expert Opin. Pharmacother., 2013, 14, 1215-1227.

30 L. Barakat, A. Jayyousi, A. Bener, B. Zuby and M. Zirie, ISRN Pharmacol., 2013, 2013, 146579.

31 P. P. De Deyn, A. F. Drenth, B. P. Kremer, R. C. Oude Voshaar and D. Van Dam, Expert Opin. Pharmacother., 2013, 14, 459-474.

32 X. Y. Cai, A. Wake and D. Gouty, Bioanalysis, 2013, 5, 517520.

33 P. Chamberlain, Bioanalysis, 2013, 5, 561-574.

34 P. Mallick and B. Kuster, Nat. Biotechnol., 2010, 28, 695-709.

35 S. L. Chen, S. L. Wu, L. J. Huang, J. B. Huang and S. H. Chen, J. Pharm. Biomed. Anal., 2013, 80, 126-135.

36 T. E. Angel, U. K. Aryal, S. M. Hengel, E. S. Baker, R. T. Kelly, E. W. Robinson and R. D. Smith, Chem. Soc. Rev., 2012, 41, 3912-3928.

37 R. Wilson, Expert Rev. Proteomics, 2013, 10, 135-149.

38 B. Domon and R. Aebersold, Science, 2006, 312, 212217.

39 P. Hernandez, M. Muller and R. D. Appel, Mass Spectrom. Rev., 2006, 25, 235-254.
40 L. Stevenson, F. Garofolo, B. Desilva, I. Dumont, S. Martinez, M. Rocci, L. Amaravadi, M. Brudny-Kloeppel, A. Musuku, B. Booth, C. Dicaire, L. Wright, L. MayrandProvencher, M. Losauro, D. Gouty, M. Arnold, S. Bansal, S. Dudal, D. Dufield, J. Duggan, C. Evans, E. Fluhler, S. Fraser, B. Gorovits, S. Haidar, R. Hayes, S. Ho, R. Houghton, R. Islam, R. Jenkins, N. Katori, S. Kaur, M. Kelley, M. Knutsson, J. Lee, H. Liu, S. Lowes, M. Ma, A. Mikulskis, H. Myler, B. Nicholson, T. Olah, E. Ormsby, S. Patel, V. Pucci, C. Ray, G. Schultz, J. Shih, R. Shoup, C. Simon, A. Song, J. Tavares Neto, V. Theobald, T. Thway, J. Wakelin-Smith, J. Wang, L. Wang, J. Welink, E. Whale, E. Woolf and R. Xu, Bioanalysis, 2013, 5, 2903-2913.

41 S. Pan, R. Aebersold, R. Chen, J. Rush, D. R. Goodlett, M. W. McIntosh, J. Zhang and T. A. Brentnall, J. Proteome Res., 2009, 8, 787-797.

42 R. S. Yalow and S. A. Berson, J. Clin. Invest., 1960, 39, 1157-1175.

43 K. B. Mullis and F. Faloona, Methods Enzymol., 1987, 155, 335-350.

44 N. L. Rosi and C. A. Mirkin, Chem. Rev., 2005, 105, 15471562.

45 M. Adler, Adv. Clin. Chem., 2005, 39, 239-292.

46 H. Zhang, Q. Zhao, X. F. Li and X. C. Le, Analyst, 2007, 132, 724-737.

47 C. M. Niemeyer, M. Adler and R. Wacker, Trends Biotechnol., 2005, 23, 208-216.

48 J. Barletta, Mol. Aspects Med., 2006, 27, 224-253.

49 M. Adler and M. Spengler, Curr. Pharm. Anal., 2009, 5, 390-407.

50 M. Adler, R. Wacker and C. M. Niemeyer, Analyst, 2008, 133, 702-718.

51 R. Y. Nong, J. Gu, S. Darmanis, M. Kamali-Moghaddam and U. Landegren, Expert Rev. Proteomics, 2012, 9, 21-32.

52 K. P. Janssen, K. Knez, D. Spasic and J. Lammertyn, Sensors, 2013, 13, 1353-1384.

53 Y. Huang, R. Shi, W. Gee and R. Bonderud, Bioanalysis, 2012, 4, 1919-1931.

54 (a) Direct side-by-side comparison studies of ELISA with alternative detection platforms using identical critical assay reagents are rarely found in peer reviewed publications because specific requirements in assay development usually limit the efforts to one technology. However, some selected examples can be found in: B. A. Leary, R. Lawrence-Henderson, C. Mallozzi, M. Fernandez Ocana, N. Duriga, D. M. O'Hara, M. Kavosi, Q. Qu and A. P. Joyce, J. Immunol. Methods, 2013, 397, 28-36; (b) S. K. Fischer, A. Joyce, M. Spengler, T. Y. Yang, Y. Zhuang, M. S. Fjording and A. Mikulskis, AAPS J., 2015, 17, 93-101.

55 H. Wei and E. Wang, Luminescence, 2011, 26, 77-85.

56 J. Todd, B. Freese, A. Lu, D. Held, J. Morey, R. Livingston and P. Goix, Clin. Chem., 2007, 53, 1990-1995.

57 S. K. Fischer, A. Joyce, M. Spengler, T. Y. Yang, Y. Zhuang, M. S. Fjording and A. Mikulskis, AAPS J., 2015, 17, 93-101. 
58 Guidance for Industry Bioanalytical Method Validation, U.S. Department of Health and Human Services, Food and Drug Administration, Center for Drug Evaluation and Research (CDER), Center for Veterinary Medicine (CVM), 2001.

59 ICH Harmonised Tripartite Guideline Validation of Analytical Procedures: Text And Methodology, International Conference on Harmonisation of Technical Requirements for Registration of Pharmaceuticals for Human Use, Q2(R1), 2005.

60 Guideline on bioanalytical method validation, European Medicines Agency, Committee for Medicinal Products for Human Use (CHMP), EMEA/CHMP/EWP/192217/2009, 2011.

61 B. DeSilva, W. Smith, R. Weiner, M. Kelley, J. Smolec, B. Lee, M. Khan, R. Tacey, H. Hill and A. Celniker, Pharm. Res., 2003, 20, 1885-1900.

62 J. W. Lee, V. Devanarayan, Y. C. Barrett, R. Weiner, J. Allinson, S. Fountain, S. Keller, I. Weinryb, M. Green, L. Duan, J. A. Rogers, R. Millham, P. J. O’Brien, J. Sailstad, M. Khan, C. Ray and J. A. Wagner, Pharm. Res., 2006, 23, 312-328.

63 M. A. Valentin, S. Ma, A. Zhao, F. Legay and A. Avrameas, J. Pharm. Biomed. Anal., 2011, 55, 869-877.

64 C. M. Niemeyer, M. Adler and D. Blohm, Anal. Biochem., 1997, 246, 140-145.

65 M. Adler, R. Wacker and C. M. Niemeyer, Biochem. Biophys. Res. Commun., 2003, 308, 240-250.

66 C. M. Niemeyer, M. Adler and R. Wacker, Nat. Protoc., 2007, 2, 1918-1930.

67 O. Stoevesandt and M. J. Taussig, New Biotechnol., 2012, 29, 511-514.

68 Y. C. Guo, Y. F. Zhou, X. E. Zhang, Z. P. Zhang, Y. M. Qiao, L. J. Bi, J. K. Wen, M. F. Liang and J. B. Zhang, Nucleic Acids Res., 2006, 34, e62.

69 B. J. Geist, A. C. Egan, T. Y. Yang, Y. Dong and G. Shankar, Bioanalysis, 2013, 5, 227-244.

70 L. E. King, S. Leung and C. Ray, Bioanalysis, 2013, 5, 14631466.

71 E. Kakizaki, T. Yoshida, H. Kawakami, M. Oseto, T. Sakai and M. Sakai, Lett. Appl. Microbiol., 1996, 23, 101-103.

72 E. R. Hendrickson, T. M. Hatfield Truby, R. D. Joerger, W. R. Majarian and R. C. Ebersole, Nucleic Acids Res., 1995, 23, 522-529.

73 K. Lind and M. Kubista, J. Immunol. Methods, 2005, 304, 107-116.

74 J. Tate and G. Ward, Clin. Biochem. Rev./Aust. Assoc. Clin. Biochemists, 2004, 25, 105-120.

75 G. Dimeski, The Clinical biochemist, Rev./Aust. Assoc. Clin. Biochemists, 2008, 29(Suppl 1), S43-S48.

76 L. J. Kricka, Clin. Chem., 1999, 45, 942-956.

77 M. Adler, M. Langer, K. Witthohn, K. Wilhelm-Ogunbiyi, P. Schoffski, P. Fumoleau and C. M. Niemeyer, J. Pharm. Biomed. Anal., 2005, 39, 972-982.

78 M. Adler, S. Schulz, R. Fischer and C. M. Niemeyer, Biochem. Biophys. Res. Commun., 2005, 333, 1289-1294.
79 E. Di Marco, G. Cangemi, M. Filippetti, G. Melioli and R. Biassoni, New Microbiol., 2007, 30, 415-421.

80 A. M. Raem and P. Rauch, Immunoassays, Springer Spektrum, Heidelberg, 2006.

81 M. Bomsel, D. Tudor, A. S. Drillet, A. Alfsen, Y. Ganor, M. G. Roger, N. Mouz, M. Amacker, A. Chalifour, L. Diomede, G. Devillier, Z. Cong, Q. Wei, H. Gao, C. Qin, G. B. Yang, R. Zurbriggen, L. Lopalco and S. Fleury, Immunity, 2011, 34, 269-280.

82 G. Leroux-Roels, C. Maes, F. Clement, F. van Engelenburg, M. van den Dobbelsteen, M. Adler, M. Amacker, L. Lopalco, M. Bomsel, A. Chalifour and S. Fleury, PloS One, 2013, 8, e55438.

83 M. Spengler, M. Adler, A. Chalifour and S. Fleury, presented in part at the American Association of Pharmaceutical Scientists (AAPS) National Biotechnology Conference, San Diego, USA, 2012.

84 M. Spengler, M. Adler, D. Jani, T. Plavina, J. Sommer and J. Goyal, presented in part at the American Association of Pharmaceutical Scientists (AAPS) National Biotechnology Conference, San Diego, USA, 2012.

85 M. Spengler, M. Adler, A. Jonas and C. M. Niemeyer, Biochem. Biophys. Res. Commun., 2009, 387, 278-282.

86 C. Pieper, B. Punnamoottil, M. Adler and M. Spengler, presented in part at the American Association of Pharmaceutical Scientists (AAPS) National Biotechnology Conference, San Francisco, USA, 2015.

87 D. Burns, L. Brunner, S. Rajendran, B. Johnson, M. Ma and J. Wang, AAPS J., 2013, 15, 123-131.

88 K. Chapman, S. Chivers, D. Gliddon, D. Mitchell, S. Robinson, T. Sangster, S. Sparrow, N. Spooner and A. Wilson, Drug Discovery Today, 2014, 19, 528-532.

89 A. P. Joyce, M. Wang, R. Lawrence-Henderson, C. Filliettaz, S. S. Leung, X. Xu and D. M. O'Hara, Pharm. Res., 2014, 31, 1823-1833.

90 L. B. Nilsson, M. Ahnoff and O. Jonsson, Bioanalysis, 2013, 5, 731-738.

91 J. M. Nam, C. S. Thaxton and C. A. Mirkin, Science, 2003, 301, 1884-1886.

92 M. C. Edwards and R. A. Gibbs, PCR Methods Appl., 1994, 3, S65-S75.

93 O. Henegariu, N. A. Heerema, S. R. Dlouhy, G. H. Vance and P. H. Vogt, Biotechniques, 1997, 23, 504-511.

94 N. M. Cirino, K. A. Musser and C. Egan, Expert Rev. Mol. Diagn., 2004, 4, 841-857.

95 C. P. Price and D. J. Newman, Principles and practice of immunoassay, Macmillan Reference Ltd., 1997.

96 S. E. Kirschbaum and A. J. Baeumner, Anal. Bioanal. Chem., 2015, 407, 3911-3926.

97 J. Li and E. Wang, Chem. Rec., 2012, 12, 177-187.

98 W. Miao, Chem. Rev., 2008, 108, 2506-2553.

99 M. M. Richter, Chem. Rev., 2004, 104, 3003-3036.

100 M. Su, W. Wei and S. Liu, Anal. Chim. Acta, 2011, 704, 16-32.

101 M. P. Bonaca, C. T. Ruff, J. Kosowsky, M. J. Conrad, S. A. Murphy, M. S. Sabatine, P. Jarolim and D. A. Morrow, 
Eur. Heart J.. Acute Cardiovasc. Care, 2013, 2, 195202.

102 A. H. Wu, N. Fukushima, R. Puskas, J. Todd and P. Goix, Clin. Chem., 2006, 52, 2157-2159.

103 S. Darmanis, R. Y. Nong, J. Vanelid, A. Siegbahn, O. Ericsson, S. Fredriksson, C. Backlin, M. Gut, S. Heath, I. G. Gut, L. Wallentin, M. G. Gustafsson, M. KamaliMoghaddam and U. Landegren, PloS One, 2011, 6, e25583.

104 Y. P. Bao, T. F. Wei, P. A. Lefebvre, H. An, L. He, G. T. Kunkel and U. R. Muller, Anal. Chem., 2006, 78, 2055-2059.

105 D. A. Morrow and E. M. Antman, Clin. Chem., 2009, 55, $5-8$.

106 K. St Ledger, S. J. Agee, M. T. Kasaian, S. B. Forlow, B. L. Durn, J. Minyard, Q. A. Lu, J. Todd, O. Vesterqvist and M. E. Burczynski, J. Immunol. Methods, 2009, 350, 161-170.

107 N. Backmann, C. Zahnd, F. Huber, A. Bietsch, A. Pluckthun, H. P. Lang, H. J. Guntherodt, M. Hegner and C. Gerber, Proc. Natl. Acad. Sci. U. S. A., 2005, 102, 14587-14592.

108 T. Braun, M. K. Ghatkesar, N. Backmann, W. Grange, P. Boulanger, L. Letellier, H. P. Lang, A. Bietsch, C. Gerber and M. Hegner, Nat. Nanotechnol., 2009, 4, 179-185.

109 F. Huber, M. Hegner, C. Gerber, H. J. Guntherodt and H. P. Lang, Biosens. Bioelectron., 2006, 21, 1599-1605.

110 S. A. Seidel, P. M. Dijkman, W. A. Lea, G. van den Bogaart, M. Jerabek-Willemsen, A. Lazic, J. S. Joseph, P. Srinivasan, P. Baaske, A. Simeonov, I. Katritch, F. A. Melo, J. E. Ladbury, G. Schreiber, A. Watts, D. Braun and S. Duhr, Methods, 2013, 59, 301-315.

111 M. Dickerson, K. Leong, K. Sheldon and L. Madison, J. Visualized Exp., 2011, 48, e2493.

112 J. T. Kindt and R. C. Bailey, Curr. Opin. Chem. Biol., 2013, 17, 818-826.

113 J. T. Kindt, M. S. Luchansky, A. J. Qavi, S. H. Lee and R. C. Bailey, Anal. Chem., 2013, 85, 10653-10657.

114 M. S. Luchansky and R. C. Bailey, Anal. Chem., 2012, 84, 793-821.

115 H. H. Gorris and D. R. Walt, Angew. Chem., Int. Ed., 2010, 49, 3880-3895.

116 D. M. Rissin, C. W. Kan, T. G. Campbell, S. C. Howes, D. R. Fournier, L. Song, T. Piech, P. P. Patel, L. Chang, A. J. Rivnak, E. P. Ferrell, J. D. Randall, G. K. Provuncher, D. R. Walt and D. C. Duffy, Nat. Biotechnol., 2010, 28, 595599.

117 D. R. Walt, Anal. Chem., 2013, 85, 1258-1263.

118 Q. Fu, J. Zhu and J. E. Van Eyk, Clin. Chem., 2010, 56, 314318.

119 P. M. Voorhees, R. F. Manges, P. Sonneveld, S. Jagannath, G. Somlo, A. Krishnan, S. Lentzsch, R. C. Frank, S. Zweegman, P. W. Wijermans, R. Z. Orlowski, B. Kranenburg, B. Hall, T. Casneuf, X. Qin, H. van de Velde, H. Xie and S. K. Thomas, Br. J. Haematol., 2013, 161, 357-366.
120 R. Dockens, J. S. Wang, L. Castaneda, O. Sverdlov, S. P. Huang, R. Slemmon, H. Gu, O. Wong, H. Li, R. M. Berman, C. Smith, C. F. Albright and G. Tong, Clin. Pharmacokinet., 2012, 51, 681-693.

121 S. Hirata, L. Dirven, Y. Shen, M. Centola, G. Cavet, W. F. Lems, Y. Tanaka, T. W. Huizinga and C. F. Allaart, Rheumatology, 2013, 7, 1202-1207.

122 R. Stockley, A. De Soyza, K. Gunawardena, J. Perrett, K. Forsman-Semb, N. Entwistle and N. Snell, Respir. Med., 2013, 107, 524-533.

123 M. Ogura, K. Hatake, K. Tobinai, T. Uchida, T. Suzuki, Y. Terui, M. Yokoyama, D. Maruyama, M. Mori, R. C. Jewell, K. Katsura and T. Hotta, Jpn. J. Clin. Oncol., 2013, 43, 466-475.

124 J. Yohrling, Bioanalysis, 2009, 1, 629-636.

125 R. K. Saiki, S. Scharf, F. Faloona, K. B. Mullis, G. T. Horn, H. A. Erlich and N. Arnheim, Science, 1985, 230, 13501354.

126 J. Swanson, Genome Technol., 2007, 23-26.

127 S. Nakamura, S. Katamine, T. Yamamoto, S. K. Foung, T. Kurata, Y. Hirabayashi, K. Shimada, S. Hino and T. Miyamoto, Virus Genes, 1993, 7, 325-338.

128 T. Sano, C. L. Smith and C. R. Cantor, Science, 1992, 258, 120-122.

129 S. Schiavo, W. C. Yang, N. H. L. Chiu and I. S. Krull, J. Immunoassay Immunochem., 2005, 26, 1-12.

130 W. R. Griswold, Mol. Immunol., 1987, 24, 1291-1294.

131 C. P. Price and D. J. Newman, Principles and practice of immunoassay, Macmillan Reference Ltd., 1997.

132 H. Zhou, R. J. Fisher and T. S. Papas, Nucleic Acids Res., 1993, 21, 6038-6039.

133 A. S. Mweene, T. Ito, K. Okazaki, E. Ono, Y. Shimizu and H. Kida, J. Clin. Microbiol., 1996, 34, 748-750.

134 H. Tsujii, Y. Okamoto, H. Nakano, K. Watanabe and T. Naraki, Int. Hepatol. Commun., 1995, 3, 154.

135 J. M. Barletta, D. C. Edelman, W. E. Highsmith and N. T. Constantine, J. Virol. Methods, 2005, 127, 154-164.

136 J. M. Nam, S. I. Stoeva and C. A. Mirkin, J. Am. Chem. Soc., 2004, 126, 5932-5933.

137 A. McKie, D. Samuel, B. Cohen and N. A. Saunders, J. Immunol. Methods, 2002, 261, 167-175.

138 C. M. Niemeyer, R. Wacker and M. Adler, Nucleic Acids Res., 2003, 31, e90.

139 P. P. Sanna, F. Weiss, M. E. Samson, F. E. Bloom and E. M. Pich, Proc. Natl. Acad. Sci. U. S. A., 1995, 92, 272275.

$140 \mathrm{~J}$. Barletta, A. Bartolome and N. T. Constantine, J. Virol. Methods, 2009, 157, 122-132.

141 R. Wacker, B. Ceyhan, P. Alhorn, D. Schueler, C. Lang and C. M. Niemeyer, Biochem. Biophys. Res. Commun., 2007, 357, 391-396.

142 T. W. Wang, H. Y. Lu, P. J. Lou and F. H. Lin, Biomaterials, 2008, 29, 4447-4454.

143 J. A. Hamilton, Trends Immunol., 2002, 23, 403-408.

144 B. Mroczko and M. Szmitkowski, Clin. Chem. Lab. Med., 2004, 42, 1347-1354. 
145 S. Sanjabi, L. A. Zenewicz, M. Kamanaka and R. A. Flavell, Curr. Opin. Pharmacol., 2009, 9, 447-453.

146 A. McKie, D. Samuel, B. Cohen and N. A. Saunders, J. Immunol. Methods, 2002, 270, 135-141.

147 S. A. Kazane, D. Sok, E. H. Cho, M. L. Uson, P. Kuhn, P. G. Schultz and V. V. Smider, Proc. Natl. Acad. Sci. U. S. A., 2012, 109, 3731-3736.

148 R. Huber, J. Eisenbraun, B. Miletzki, M. Adler and C. Gleiter, Phytomedicine, 2007, SVII(30), 50.

149 P. Schoffski, S. Riggert, P. Fumoleau, M. Campone, O. Bolte, S. Marreaud, D. Lacombe, B. Baron, M. Herold, H. Zwierzina, K. Wilhelm-Ogunbiyi, H. Lentzen and C. Twelves, Ann. Oncol., 2004, 15, 1816-1824.

150 M. Nemansky, presented in part at the European Bioanalysis Forum (EBF) 3rd Open Meeting - From Challenges to Solutions -, Barcelona, 2010.

151 M. Spengler, presented in part at the European Bioanalysis Forum (EBF) 3rd Open Meeting - From Challenges to Solutions -, Barcelona, 2010.

152 L. M. Londono, E. J. Tarcha, M. Adler, B. Punnamoottil and S. P. Iadonato, presented in part at the EBF 6th Open Meeting - Moving Forward Together -, Barcelona, 2013.

153 M. Spengler and M. Adler, presented in part at the American Association of Pharmaceutical Scientists (AAPS) National Biotechnology Conference, San Diego, USA, 2012.

154 P. Timmerman, N. Henderson, J. Smeraglia, H. Mulder, B. Ingelse, M. Brudny-Kloeppel and A. Companjen, Bioanalysis, 2013, 5, 139-145.

155 J. M. Barletta, D. C. Edelman and N. T. Constantine, Am. J. Clin. Pathol., 2004, 122, 20-27.

156 P. Tian and R. Mandrell, J. Appl. Microbiol., 2006, 100, 564-574.

157 T. C. Chang and S. H. Huang, J. Immunol. Methods, 1997, 208, 35-42.

158 N. Henterich, A. A. Osman, E. Mendez and T. Mothes, Nahrung, 2003, 47, 345-348.

159 H. Y. Chao, Y. C. Wang, S. S. Tang and H. W. Liu, Toxicon, 2004, 43, 27-34.

160 H. C. Wu, Y. L. Huang, S. C. Lai, Y. Y. Huang and M. F. Shaio, Lett. Appl. Microbiol., 2001, 32, 321-325.

161 R. C. Allen, S. Rogelj, S. E. Cordova and T. L. Kieft, J. Immunol. Methods, 2006, 308, 109-115.

162 A. Rajkovic, B. El-Moualij, M. Uyttendaele, P. Brolet, W. Zorzi, E. Heinen, E. Foubert and J. Debevere, Appl. Environ. Microbiol., 2006, 72, 6593-6599.

163 A. S. McElhinny, G. E. Exley and C. M. Warner, Am. J. Reprod Immunol., 2000, 44, 52-58.

164 A. S. McElhinny, N. Kadow and C. M. Warner, Mol. Hum. Reprod., 1998, 4, 966-971.

165 C. Moser, M. Amacker, A. R. Kammer, S. Rasi, N. Westerfeld and R. Zurbriggen, Expert Rev. Vaccines, 2007, 6, 711-721.

166 C. Moser, M. Amacker and R. Zurbriggen, Expert Rev. Vaccines, 2011, 10, 437-446.

167 J. Wilschut, Immunol. Lett., 2009, 122, 118-121.
168 M. C. Case, A. D. Burt, J. Hughes, J. M. Palmer, J. D. Collier, M. F. Bassendine, S. J. Yeaman, M. A. Hughes and G. N. Major, J. Immunol. Methods, 1999, 223, 93-106.

169 P. Diel, T. Schiffer, S. Geisler, T. Hertrampf, S. Mosler, S. Schulz, K. F. Wintgens and M. Adler, Mol. Cell. Endocrinol., 2010, 330, 1-9.

170 P. Lees, F. M. Cunningham and J. Elliott, J. Vet. Pharmacol. Ther., 2004, 27, 397-414.

171 R. Nakaoke, S. Sakaguchi, R. Atarashi, N. Nishida, K. Arima, K. Shigematsu and S. Katamine, Cell Mol. Neurobiol., 2000, 20, 717-730.

172 C. Luk, Y. Compta, N. Magdalinou, M. J. Marti, G. Hondhamuni, H. Zetterberg, K. Blennow, R. Constantinescu, Y. Pijnenburg, B. Mollenhauer, C. Trenkwalder, J. Van Swieten, W. Z. Chiu, B. Borroni, A. Camara, P. Cheshire, D. R. Williams, A. J. Lees and R. de Silva, J. Neurochem., 2012, 123, 396-405.

173 P. J. Visser and D. S. Knopman, Neurology, 2009, 73, 744745 .

174 Z. Nagy, M. M. Esiri, K. A. Jobst, J. H. Morris, E. M. King, B. McDonald, S. Litchfield, A. Smith, L. Barnetson and A. D. Smith, Dementia, 1995, 6, 21-31.

175 A. N. da Costa, M. Spengler, M. Adler, J.-P. Courade and J. Smeraglia, presented in part at the American Association of Pharmaceutical Scientists (AAPS) National Biotechnology Conference, San Francisco, USA, 2015.

176 S. Flunkert, M. Hierzer, T. Loffler, R. Rabl, J. Neddens, S. Duller, E. L. Schofield, M. A. Ward, M. Posch, H. Jungwirth, M. Windisch and B. Hutter-Paier, J. Neurodegener. Dis., 2013, 11, 194-205.

177 T. S. Khurana and K. E. Davies, Nat. Rev. Drug Discovery, 2003, 2, 379-390.

178 K. R. Wagner, J. L. Fleckenstein, A. A. Amato, R. J. Barohn, K. Bushby, D. M. Escolar, K. M. Flanigan, A. Pestronk, R. Tawil, G. I. Wolfe, M. Eagle, J. M. Florence, W. M. King, S. Pandya, V. Straub, P. Juneau, K. Meyers, C. Csimma, T. Araujo, R. Allen, S. A. Parsons, J. M. Wozney, E. R. Lavallie and J. R. Mendell, Ann. Neurol., 2008, 63, 561-571.

179 D. Furuya, A. Yagihashi, T. Yajima, D. Kobayashi, K. Orita, M. Kurimoto and N. Watanabe, J. Immunol. Methods, 2000, 238, 173-180.

180 M. Komatsu, D. Kobayashi, K. Saito, D. Furuya, A. Yagihashi, H. Araake, N. Tsuji, S. Sakamaki, Y. Niitsu and N. Watanabe, Clin. Chem., 2001, 47, 12971301.

181 K. Saito, D. Kobayashi, M. Sasaki, H. Araake, T. Kida, A. Yagihashi, T. Yajima, H. Kameshima and N. Watanabe, Clin. Chem., 1999, 45, 665-669.

182 N. Watanabe, Rinsho Byori, 2001, 49, 829-833.

183 A. J. Fleetwood, A. D. Cook and J. A. Hamilton, Crit. Rev. Immunol., 2005, 25, 405-428.

184 J. A. Hamilton and G. P. Anderson, Growth Factors, 2004, 22, 225-231. 
185 W. Xu, X. Zhao, M. R. Daha and C. van Kooten, Mol. Immunol., 2013, 53, 179-186.

186 A. Ruiz-Garcia, M. Bermejo, A. Moss and V. G. Casabo, J. Pharm. Sci., 2008, 97, 654-690.

187 C. Li, B. Liu, J. Chang, T. Groessl, M. Zimmerman, Y. Q. He, J. Isbell and T. Tuntland, Drug Discovery today, 2013, 18, 71-78.

188 T. N. Thompson, Curr. Drug Metab., 2000, 1, 215-241.

189 V. Chi, M. W. Pennington, R. S. Norton, E. J. Tarcha, L. M. Londono, B. Sims-Fahey, S. K. Upadhyay, J. T. Lakey, S. Iadonato, H. Wulff, C. Beeton and K. G. Chandy, Toxicon, 2012, 59, 529-546.

190 E. J. Tarcha, V. Chi, E. J. Munoz-Elias, D. Bailey, L. M. Londono, S. K. Upadhyay, K. Norton, A. Banks, I. Tjong, H. Nguyen, X. Hu, G. W. Ruppert, S. E. Boley, R. Slauter, J. Sams, B. Knapp, D. Kentala, Z. Hansen, M. W. Pennington, C. Beeton, K. G. Chandy and S. P. Iadonato, J. Pharmacol. Exp. Ther., 2012, 342, 642-653.

191 S. K. Upadhyay, K. L. Eckel-Mahan, M. R. Mirbolooki, I. Tjong, S. M. Griffey, G. Schmunk, A. Koehne, B. Halbout, S. Iadonato, B. Pedersen, E. Borrelli, P. H. Wang, J. Mukherjee, P. Sassone-Corsi and K. G. Chandy, Proc. Natl. Acad. Sci. U. S. A., 2013, 110, E2239-E2248.

192 H. P. Rang and M. M. Dale, Rang and Dale's pharmacology, Elsevier Churchill Livingstone, Edinburgh, 7th edn, 2012, pp. xxii, 777 p.

193 X. Chen, J. L. Zaro and W. C. Shen, Adv. Drug Delivery Rev., 2013, 65, 1357-1369.

194 D. Jani, E. Savino and J. Goyal, Bioanalysis, 2015, 7, 285294.

195 L. Vermet, M. Spengler, H. Schroeder and P. Cortez, presented in part at the American Association of Pharmaceutical Scientists (AAPS) National Biotechnology Conference, San Diego, USA, 2014.

196 O. Soderberg, M. Gullberg, M. Jarvius, K. Ridderstrale, K. J. Leuchowius, J. Jarvius, K. Wester, P. Hydbring, F. Bahram, L. G. Larsson and U. Landegren, Nat. Methods, 2006, 3, 995-1000.

197 O. Soderberg, K. J. Leuchowius, M. Kamali-Moghaddam, M. Jarvius, S. Gustafsdottir, E. Schallmeiner, M. Gullberg, J. Jarvius and U. Landegren, Genet Eng., 2007, 28, 85-93.

198 E. Jablonski and T. Adams, Medical Device, 2006, IVDT 2006.

199 S. B. Thorsen, M. Lundberg, A. Villablanca, S. L. Christensen, K. C. Belling, B. S. Nielsen, M. Knowles, N. Gee, H. J. Nielsen, N. Brunner, I. J. Christensen, S. Fredriksson, J. Stenvang and E. Assarsson, J. Transl. Med., 2013, 11, 253.

200 S. Fredriksson, M. Gullberg, J. Jarvius, C. Olsson, K. Pietras, S. M. Gustafsdottir, A. Ostman and U. Landegren, Nat. Biotechnol., 2002, 20, 473-477.

201 S. M. Gustafsdottir, E. Schallmeiner, S. Fredriksson, M. Gullberg, O. Soderberg, M. Jarvius, J. Jarvius, M. Howell and U. Landegren, Anal. Biochem., 2005, 345, 2-9.
202 L. Zhu, H. Koistinen, P. Wu, A. Narvanen, E. Schallmeiner, S. Fredriksson, U. Landegren and U. H. Stenman, Biol. Chem., 2006, 387, 769-772.

203 M. Gullberg, S. Fredriksson, M. Taussig, J. Jarvius, S. Gustafsdottir and U. Landegren, Curr. Opin. Biotechnol., 2003, 14, 82-86.

204 M. Gullberg, S. M. Gustafsdottir, E. Schallmeiner, J. Jarvius, M. Bjarnegard, C. Betsholtz, U. Landegren and S. Fredriksson, Proc. Natl. Acad. Sci. U. S. A., 2004, 101, 8420-8424.

205 S. Darmanis, R. Y. Nong, M. Hammond, J. Gu, A. Alderborn, J. Vanelid, A. Siegbahn, S. Gustafsdottir, O. Ericsson, U. Landegren and M. Kamali-Moghaddam, Mol. Cell. Proteomics, 2010, 9, 327-335.

206 J. Goransson, R. Ke, R. Y. Nong, W. M. Howell, A. Karman, J. Grawe, J. Stenberg, M. Granberg, M. Elgh, D. Herthnek, P. Wikstrom, J. Jarvius and M. Nilsson, PloS One, 2012, 7, e31068.

207 M. L. Metzker, Nat. Rev. Genet., 2010, 11, 31-46.

208 J. M. Rizzo and M. J. Buck, Cancer Prevention Res., 2012, 5, 887-900.

209 J. Zhang, R. Chiodini, A. Badr and G. Zhang, J. Genet. Genomics, 2011, 38, 95-109.

210 R. Ke, R. Y. Nong, S. Fredriksson, U. Landegren and M. Nilsson, PLoS One, 2013, 8, e69813.

211 J. Jarvius, J. Melin, J. Goransson, J. Stenberg, S. Fredriksson, C. Gonzalez-Rey, S. Bertilsson and M. Nilsson, Nat. Methods, 2006, 3, 725-727.

212 D. Recupero, L. Daniele, C. Marchio, L. Molinaro, I. Castellano, P. Cassoni, A. Righi, F. Montemurro, P. Sismondi, N. Biglia, G. Viale, M. Risio and A. Sapino, J. Pathol., 2013, 229, 390-399.

213 P. C. Ho, Y. C. Tsui, X. Feng, D. R. Greaves and L. N. Wei, Nat. Immunol., 2012, 13, 379-386.

214 A. W. Fjorback, M. Seaman, C. Gustafsen, A. Mehmedbasic, S. Gokool, C. Wu, D. Militz, V. Schmidt, P. Madsen, J. R. Nyengaard, T. E. Willnow, E. I. Christensen, W. B. Mobley, A. Nykjaer and O. M. Andersen, J. Neurosci., 2012, 32, 14671480 .

215 J. Schlingemann, M. Leijon, A. Yacoub, H. Schlingemann, S. Zohari, A. Matyi-Toth, I. Kiss, G. Holmquist, A. Nordengrahn, U. Landegren, B. Ekstrom and S. Belak, J. Virol. Methods, 2010, 163, 116-122.

216 H. H. Lin, E. Bell, D. Uwanogho, L. W. Perfect, H. Noristani, T. J. Bates, V. Snetkov, J. Price and Y. M. Sun, Stem Cells, 2010, 28, 1950-1960.

217 T. Conze, A. Shetye, Y. Tanaka, J. Gu, C. Larsson, J. Goransson, G. Tavoosidana, O. Soderberg, M. Nilsson and U. Landegren, Annu. Rev. Anal. Chem., 2009, 2, 215239.

218 A. Blokzijl, M. Friedman, F. Ponten and U. Landegren, J. Internal Med., 2010, 268, 232-245.

219 A. Zieba, K. Grannas, O. Soderberg, M. Gullberg, M. Nilsson and U. Landegren, New Biotechnol., 2012, 29, 634-640. 
220 G. Li, X. Ruan, R. K. Auerbach, K. S. Sandhu, M. Zheng, P. Wang, H. M. Poh, Y. Goh, J. Lim, J. Zhang, H. S. Sim, S. Q. Peh, F. H. Mulawadi, C. T. Ong, Y. L. Orlov, S. Hong, Z. Zhang, S. Landt, D. Raha, G. Euskirchen, C. L. Wei, W. Ge, H. Wang, C. Davis, K. I. Fisher-Aylor, A. Mortazavi, M. Gerstein, T. Gingeras, B. Wold, Y. Sun, M. J. Fullwood, E. Cheung, E. Liu, W. K. Sung, M. Snyder and Y. Ruan, Cell, 2012, 148, 84-98.

221 R. Lasserre, C. Cuche, R. Blecher-Gonen, E. Libman, E. Biquand, A. Danckaert, D. Yablonski, A. Alcover and V. Di Bartolo, J. Cell Biol., 2011, 195, 839-853.

222 K. J. Leuchowius, M. Jarvius, M. Wickstrom, L. Rickardson, U. Landegren, R. Larsson, O. Soderberg, M. Fryknas and J. Jarvius, Mol. Cell. Proteomics, 2010, 9, 178-183.

223 P. Muller, E. Ruckova, P. Halada, P. J. Coates, R. Hrstka, D. P. Lane and B. Vojtesek, Oncogene, 2013, 32, 31013110.

224 U. Landegren, E. Schallmeiner, M. Nilsson, S. Fredriksson, J. Baner, M. Gullberg, J. Jarvius, S. Gustafsdottir, F. Dahl, O. Soderberg, O. Ericsson and J. Stenberg, J. Mol. Recognit., 2004, 17, 194-197.

225 G. Blandin, S. Marchand, K. Charton, N. Daniele, E. Gicquel, J. B. Boucheteil, A. Bentaib, L. Barrault, D. Stockholm, M. Bartoli and I. Richard, Skeletal Muscle, 2013, 3, 3 .

226 N. Jonckheere, N. Skrypek, J. Merlin, A. F. Dessein, P. Dumont, E. Leteurtre, A. Harris, J. L. Desseyn, C. Susini, F. Frenois and I. Van Seuningen, PloS One, 2012, 7, e32232.

227 N. Satta, E. K. Kruithof, C. Fickentscher, S. DunoyerGeindre, F. Boehlen, G. Reber, D. Burger and P. de Moerloose, Blood, 2011, 117, 5523-5531.

228 C. Lu, D. J. Stewart, J. J. Lee, L. Ji, R. Ramesh, G. Jayachandran, M. I. Nunez, I. I. Wistuba, J. J. Erasmus, M. E. Hicks, E. A. Grimm, J. M. Reuben, V. Baladandayuthapani, N. S. Templeton, J. D. McMannis and J. A. Roth, PloS One, 2012, 7, e34833.

229 J. Leja, D. Yu, B. Nilsson, L. Gedda, A. Zieba, T. Hakkarainen, G. Akerstrom, K. Oberg, V. Giandomenico and M. Essand, Gene Ther., 2011, 18, 1052-1062.

230 D. Sulakhe, S. Balasubramanian, B. Xie, E. Berrocal, B. Feng, A. Taylor, B. Chitturi, U. Dave, G. Agam, J. Xu, D. Bornigen, I. Dubchak, T. C. Gilliam and N. Maltsev, Adv. Exp. Med. Biol., 2014, 799, 39-67.

231 E. Assarsson, M. Lundberg, G. Holmquist, J. Bjorkesten, S. B. Thorsen, D. Ekman, A. Eriksson, E. Rennel Dickens, S. Ohlsson, G. Edfeldt, A. C. Andersson, P. Lindstedt, J. Stenvang, M. Gullberg and S. Fredriksson, PloS One, 2014, 9, e95192.

232 S. Fredriksson, J. Horecka, O. T. Brustugun, J. Schlingemann, A. C. Koong, R. Tibshirani and R. W. Davis, Clin. Chem., 2008, 54, 582-589.

233 U. Landegren, J. Vanelid, M. Hammond, R. Y. Nong, D. Wu, E. Ulleras and M. Kamali-Moghaddam, Anal. Chem., 2012, 84, 1824-1830.
234 M. Lundberg, S. B. Thorsen, E. Assarsson, A. Villablanca, B. Tran, N. Gee, M. Knowles, B. S. Nielsen, E. Gonzalez Couto, R. Martin, O. Nilsson, C. Fermer, J. Schlingemann, I. J. Christensen, H. J. Nielsen, B. Ekstrom, C. Andersson, M. Gustafsson, N. Brunner, J. Stenvang and S. Fredriksson, Mol. Cell. Proteomics, 2011, 10, M110 004978.

235 A. Blokzijl, R. Nong, S. Darmanis, E. Hertz, U. Landegren and M. Kamali-Moghaddam, Biochim. Biophys. Acta, 2014, 1844, 933-939.

236 N. L. Anderson, Clin. Chem., 2010, 56, 177-185.

237 C. Solier and H. Langen, Proteomics, 2014, 14, 774-783.

238 D. A. Giljohann and C. A. Mirkin, Nature, 2009, 462, 461464.

239 J. M. Nam, K. J. Jang and J. T. Groves, Nat. Protoc., 2007, 2, 1438-1444.

240 J. M. Nam, A. R. Wise and J. T. Groves, Anal. Chem., 2005, 77, 6985-6988.

241 C. S. Thaxton, D. G. Georganopoulou and C. A. Mirkin, Clin. Chim. Acta, 2006, 363, 120-126.

242 D. A. Giljohann, D. S. Seferos, W. L. Daniel, M. D. Massich, P. C. Patel and C. A. Mirkin, Angew. Chem., Int. Ed., 2010, 49, 3280-3294.

243 J. Ren, Z. Chen, S. J. Juan, X. Y. Yong, B. R. Pan and D. M. Fan, Cancer, 2000, 88, 280-285.

244 J. J. Storhoff and C. A. Mirkin, Chem. Rev., 1999, 99, 18491862.

245 T. L. Chang, C. Y. Tsai, C. C. Sun, C. C. Chen, L. S. Kuo and P. H. Chen, Biosens. Bioelectron., 2007, 22, 3139-3145.

246 S. Tang, J. Zhao, J. J. Storhoff, P. J. Norris, R. F. Little, R. Yarchoan, S. L. Stramer, T. Patno, M. Domanus, A. Dhar, C. A. Mirkin and I. K. Hewlett, J. Acquired Immune Defic. Syndr., 2007, 46, 231-237.

247 H. Q. Yin, M. X. Jia, S. Yang, S. Q. Wang and J. G. Zhang, Toxicon, 2012, 59, 12-16.

248 Y. Tang, H. Wang, J. Xiang, Y. Chen, W. He, N. Deng and H. Yang, Anal. Chim. Acta, 2010, 657, 210-214.

249 D. Zhang, D. J. Carr and E. C. Alocilja, Biosens. Bioelectron., 2009, 24, 1377-1381.

250 M. Dodemont, R. De Mendonca, C. Nonhoff, S. Roisin and O. Denis, J. Clin. Microbiol., 2014, 52, 3085-3087.

251 M. S. Lionakis and M. G. Netea, PLoS Pathog., 2013, 9, e1003079.

252 J. Mestas, C. M. Polanco, S. Felsenstein and J. Dien Bard, J. Clin. Microbiol., 2014, 52, 283-287.

253 H. Dong, J. Liu, H. Zhu, C. Y. Ou, W. Xing, M. Qiu, G. Zhang, Y. Xiao, J. Yao, P. Pan and Y. Jiang, Virol. J., 2012, 9, 180.

254 E. Y. Kim, J. Stanton, B. T. Korber, K. Krebs, D. Bogdan, K. Kunstman, S. Wu, J. P. Phair, C. A. Mirkin and S. M. Wolinsky, Nanomedicine, 2008, 3, 293-303.

255 H. Q. Yin, M. X. Jia, L. J. Shi, S. Yang, L. Y. Zhang, Q. M. Zhang, S. Q. Wang, G. Li and J. G. Zhang, J. Virol. Methods, 2011, 178, 225-228.

256 H. J. Cho, J. W. Jang, S. Y. Ko, S. H. Choi, C. S. Lim and S. S. An, J. Med. Virol., 2014, 1, 18-24. 
257 C. S. Thaxton, R. Elghanian, A. D. Thomas, S. I. Stoeva, J. S. Lee, N. D. Smith, A. J. Schaeffer, H. Klocker, W. Horninger, G. Bartsch and C. A. Mirkin, Proc. Natl. Acad. Sci. U. S. A., 2009, 106, 18437-18442.

258 X. Zhang, B. Qi, Y. Li and S. Zhang, Biosens. Bioelectron., 2009, 25, 259-262.

259 J. F. Loo, P. M. Lau, H. P. Ho and S. K. Kong, Talanta, 2013, 115, 159-165.
260 I. P. Lau, E. K. Ngan, J. F. Loo, Y. K. Suen, H. P. Ho and S. K. Kong, Biochem. Biophys. Res. Commun., 2010, 395, 560-564.

261 S. Lehmann, C. Delaby, J. Vialaret, J. Ducos and C. Hirtz, Clin. Chem. Lab. Med., 2013, 51, 18971909.

262 R. J. Meesters and G. P. Hooff, Bioanalysis, 2013, 5, 21872208. 